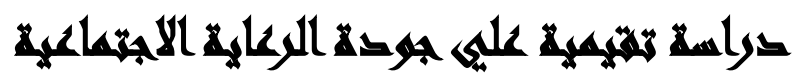

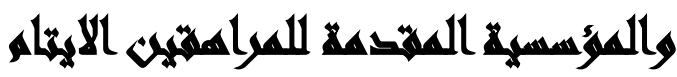

\section{[11]}

\author{
منى محمد عبده عثمان (')- أمل عبد الفتاح شمس الاين(r) (َ)

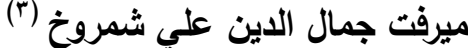

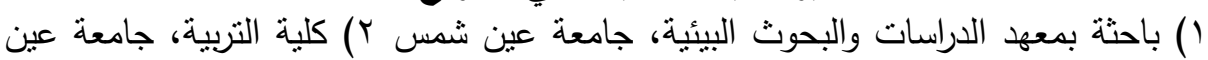
شمس ץ) كلية الخدمة الاجتماعية، جامعة حلوان

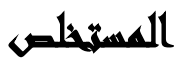

هدفت هذه الدراسة إلي تقييم مدي جودة الرعاية الاجتماعية والمؤسسية المقدمة للأيتام

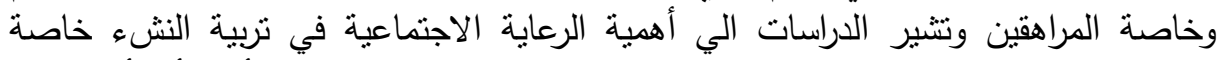

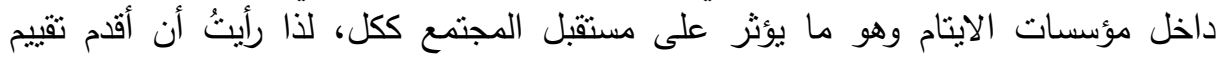

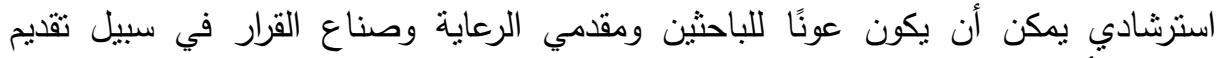

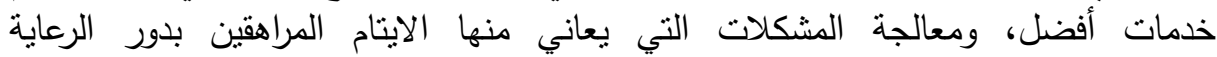

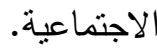

وشملت عينة الدراسة علي (·) (ب) حالة مفردة للأخصائيين مقدمي الرعاية بمؤسسات

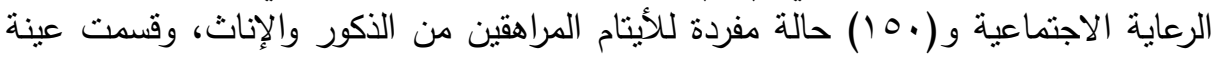

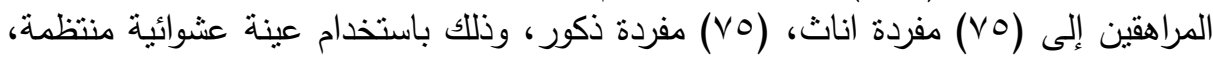

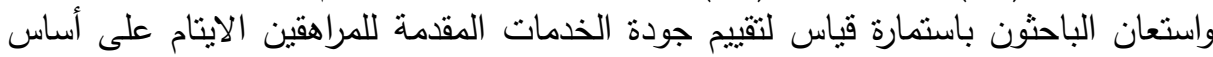

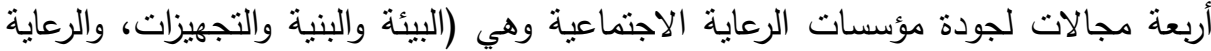
المتكاملة، وحماية الطفل، والإدارة الفعالة). بعد ذلك قمت بتصنيف هذه الإدارة البيانات - تبعا لكل استمارة- بأن وضعت الانواع

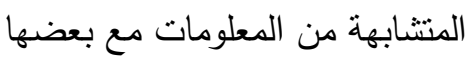

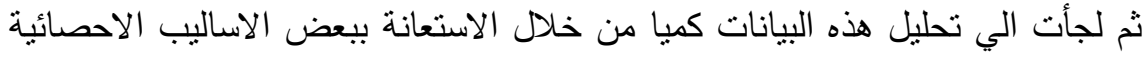

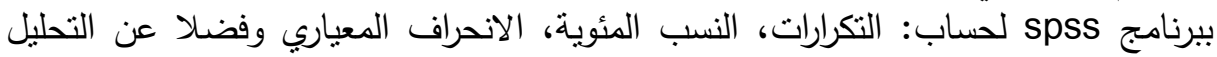

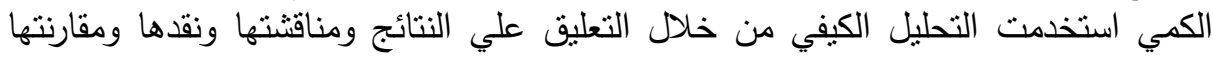


وقد توصلت الدراسة الراهنة للنتائج التاليـة:

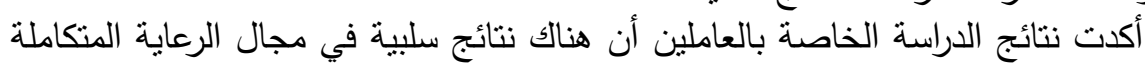
وانعكاسها بصورة سلبية وقصور شديد في برامج الرعاية اللاحقة .

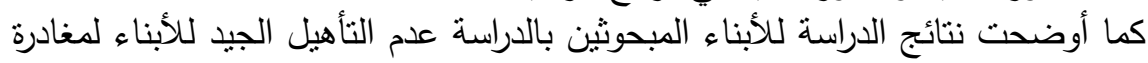
المؤسسة مغادرة امنة للرعاية اللاحقة. وتبين أن المعايير المطبقة علي هذهة الماتية المؤسسات لم يدرج بها مؤشرات كافية لبرامج

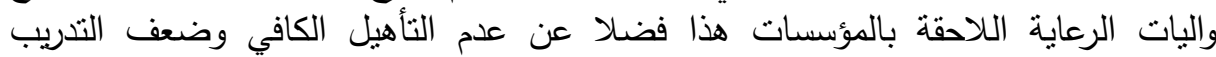

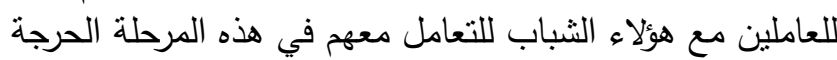

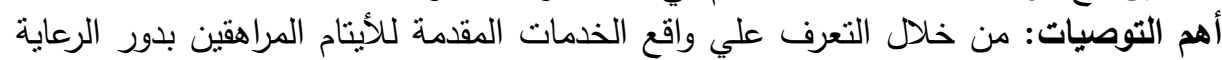

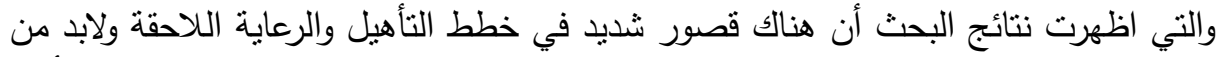

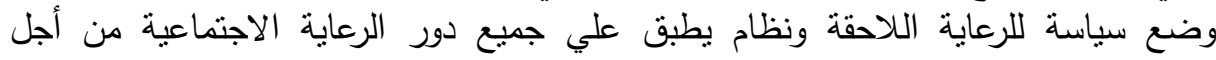

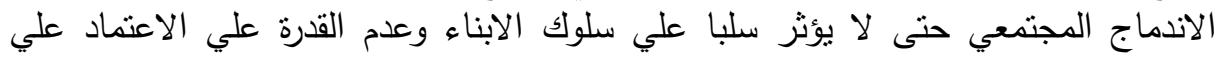

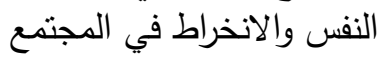

\section{rasall}

منذ آلاف السنين كان المجتمع دائماً ما يواجه مسئولية رعاية أنواع مختلفة من المشكلات الخاصة بالطفولة، وفي أغلب هذه المشكلات كان السبب الأساسي الذي داني يدفع المجتمع لتحمل مسئوليات رعاية الأطفال هو حالة الضعف أو العجز التي كان عليها

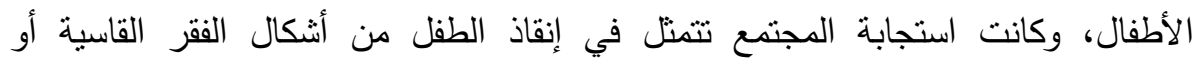

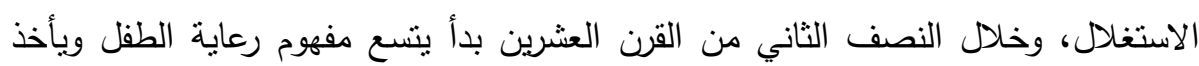

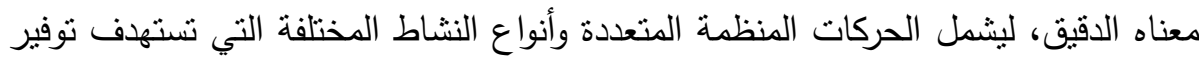

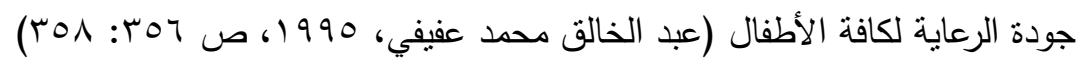
تهنم العلوم الانسانية بحقوق الإنسان في المقام الأول واتفاقية حقوق الطفل (919 (19) )

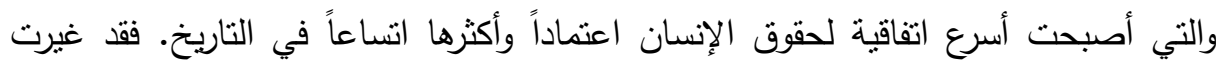
الاتفاقية الطريقة التي ينظر فيها إلى الأطفال ومعاملتهم كبشر يتمتعون بمجموعة متميزة من الإنسان

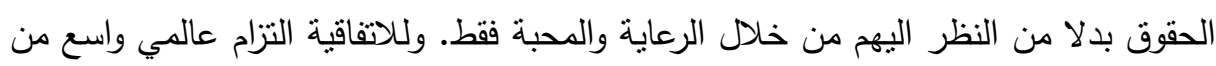

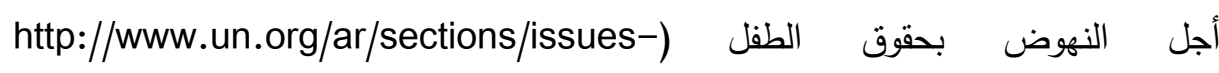


ذله depth/children/index.html ذللك فهي تهنم بالأيتام المراهقين كفئة في حاجة إلى رعاية خاصة لرنة إن نقطة الانطلاق الأولى والبداية الصحيحة في استراتيجيات التتمية هي رعائية إلى رعايه وحماية الأطفال، وذلك لأن اطفال اليوم هي القوى البشرية الفاعلة في مستقبل الغد.

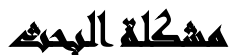

تتشكلت أهمية البحث من منطلق الاهتمام المجتمي بتلك الفئة المهمشة الضعيفة التي تحتاج لمد يد العون ودور هذه الفئة واهميتها بالمجتمع، فحسب احصاءات الجهاز المركزي

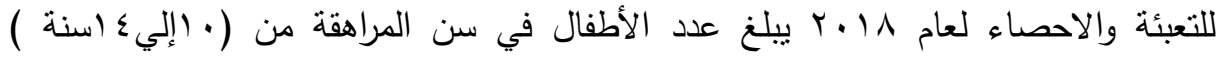
9, 9, VY... 9, I \& . . .

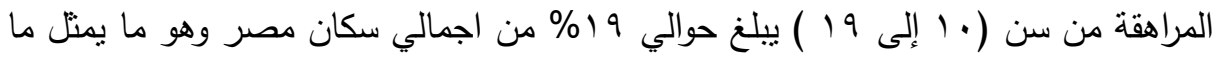
يقرب من خمس عدد السكان بجمهورية مصر العربية. (الجهاز المركزي للتعبئة العامة

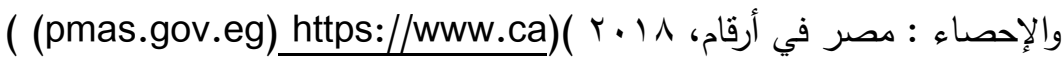
وحيث أن عدد المودعين بدور الايتام حسب احصاءات وزارة التضامن الاجتماعي لعام

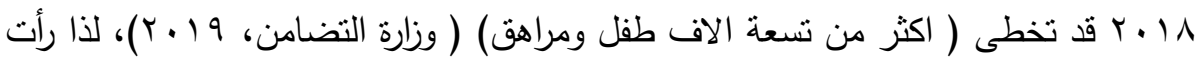

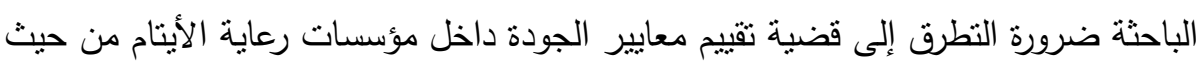

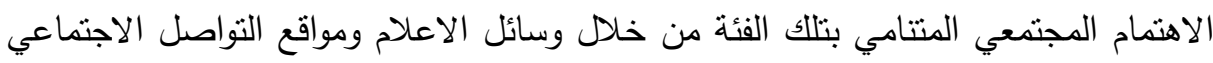
لهؤلاء المراهقين بمؤسسات الرعاية الاجتماعية وما يقدم لهم من برامج وانشطة أو خدمات

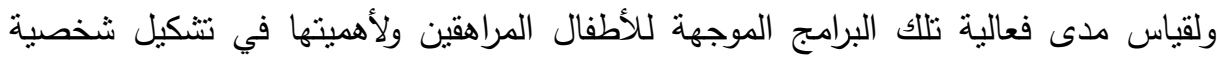

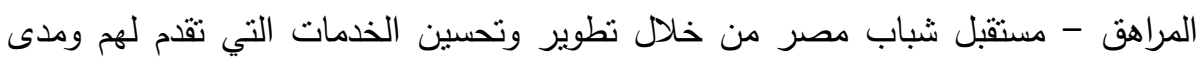
الاستفادة من تطبيق معايير محددة للجودة داخل تللك المؤسسات في تأهيلهم ومساعدتهم للدمج

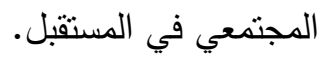




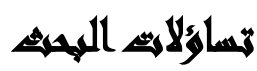

يتحدد التساؤل الرئيسي للبحث في: هل تسهم معايير الجودة وبرامج الرعاية الاجتماعية التي تتبناها وزارة التضامن الاجتماعي في تحقيق جودة الرعاية الاجتماعية بالمؤسسات الأهلية

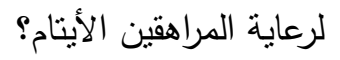
ا ـ ـ ما واقع مؤسسات الرعاية الاجتماعية للأيتام ؟

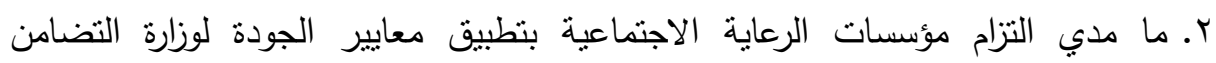

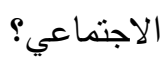
r. ما المقترحات والتعديلات اللازمة علي المعايير الحالية بما يسهم فى جودة مؤسسات الرعاية الاجتماعية؟ ماتج

\section{أهما اهث المهيث}

ا ـ. التعرف علي واقع مؤسسات الرعاية الاجتماعية للإيتام

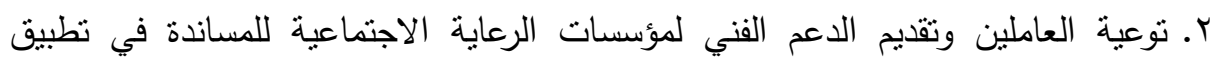
معايير الجودة لتحقيق حباة افضل للمراهقين المقيمين بمؤسسات الرعاية الاجتماعية.

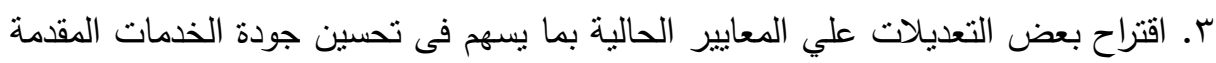

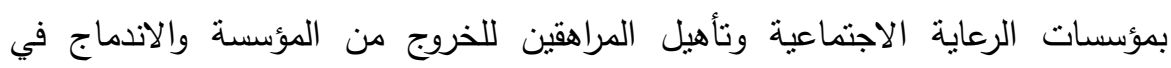
المجتمع.

\section{Aath}

حدود جغرافية: مجتمع محلى يشمل دور الرعاية ومؤسسات الرعاية التي بها ايتام مراهقين حدود المكان: محافظة القاهرة - خمس مؤسسات مختلفة حدود الزمن: من rا شهر حتى بس شهر •

\section{منهمج المهيث}

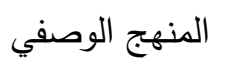




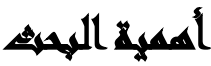

أولاً: الأهمية الأكاديمية: الوصول لبعض الخبرات الميدانية التي قد تسهم في إثراء الجانب المعرفي في مجال رعاية الايتام . المان. ثانياً: الأهمية التطبيقية: تكمن في المساهمة في تحسين جودة الرعاية المقدمة للمراهقين الايتام بدور الرعاية وهي بمثابة دليل اجرائي لمساعدة العاملين في هذا المجال من الاستفادة

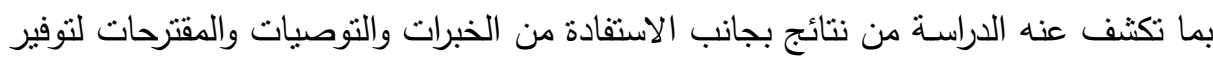
حياة كريمة للأطفال والمراهقين بدور الرعاية ومن ثم فالبحث مرجع مفيد لكل الباحثين المهتمين بقضايا الايتام كما يمكن الاستفادة من البحث في تطبيق معايير جودة مؤسسات الرعاية الاجتماعية وتطوير البرامج والخدمات المقدمة داخل مؤسسات الايتام وكيفية تأهيل الأبناء بهذه المؤسسات للرعاية اللاحقة.

\section{همطلحاهي المهيه}

1. التقييم Evaluation : يعدّ التقييم ظاهرة إنسانية فردية قبل أن تكون مؤسسية، والتقييم

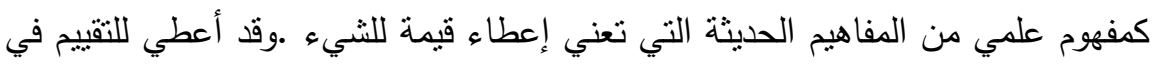

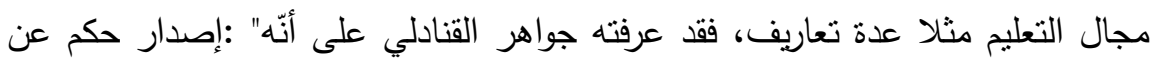

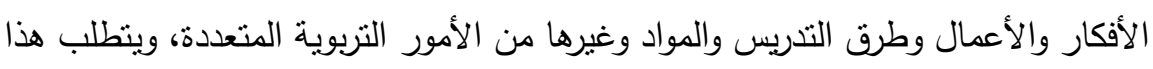

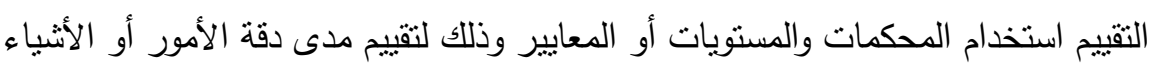

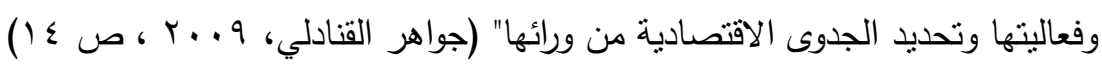

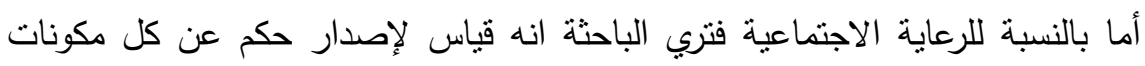

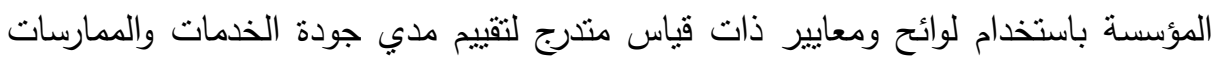

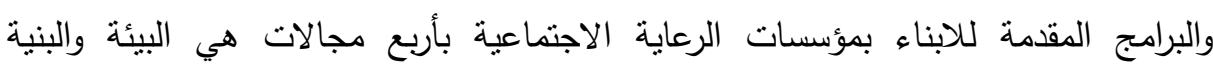
والتجهيزات، الرعاية المتكاملة، حماية الطفل ومناصرته، الادارة الفعالة. 
r. الجودة the quality إدارة الجودة الثاملة تعني المفاهيم الإدارية الحديثة التي تستهدف جودة الخدمات والمنتجات وجودة الأداء ومن خلالها يتم العمل بشكل شامل يتضامن فيه جميع العاملين لتحقيق الأهداف .

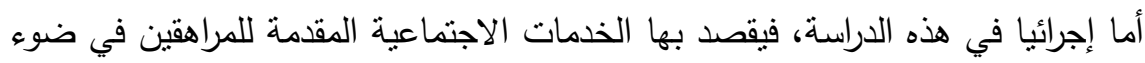
مفهوم إدارة الجودة الثاملة: هي الخدمات التي يقدمها مقدم الرعاية (مدير مؤسسة، اخصائي

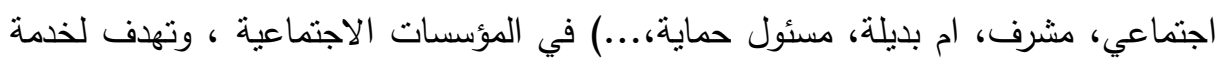

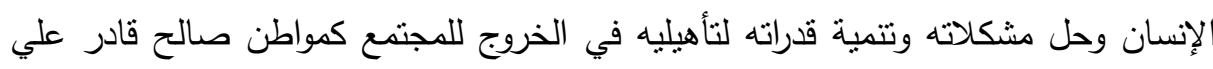
مواجهة الحياة والاندماج في المجتمع بمعاونة ومشاركة جميع العاملين في الإدارات والأقسام

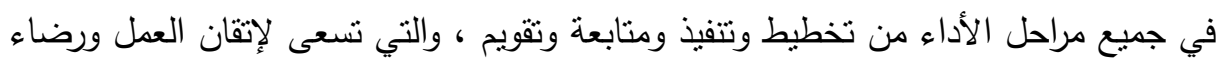
المراهقين وتتسم بالكفاءة والفعالية وتقدم بأفضل الطرق.

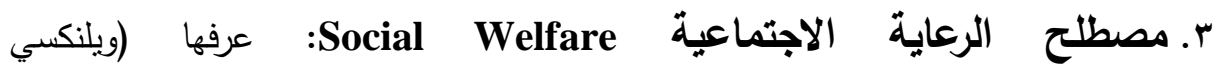
(Wilensky

أجل الوصول إلى نظوير الظروف الاقتصادية والصحية لسكان المجتمع أو جزء منها. وعرفها عبد المنعم شوقي: الرعاية لاجتماعية هي تتظيم يهدف إلى مساعدة الإنسان

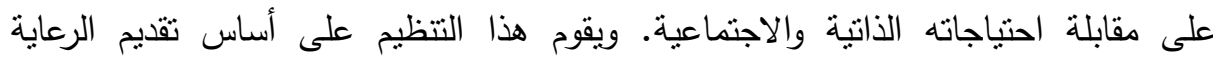

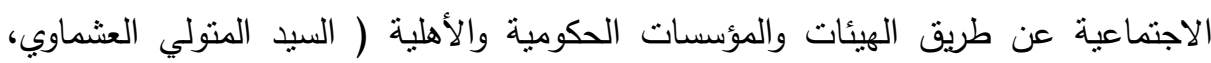

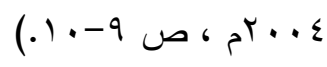
ونخرج من هذا التعريف بما يلي: - خدمات الرعاية الاجتماعية خدمات منظمة ومخططة.

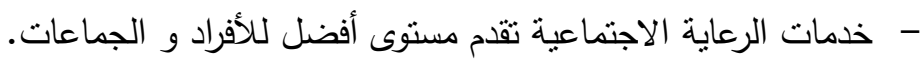
تساعد برامج الرعاية الاجتماعية على توفير الظروف التي نساعد على تتمية ونمو التهو

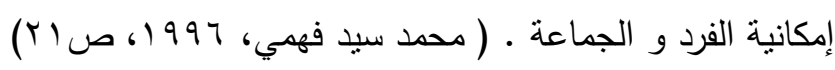

\section{گ مصطلح اليتيم المراهق Orphan Teenager} المراهث teenager: تعد المراهقة أحد المراحل الحرجة التى يمر بها الطفل وتعني في اللغة

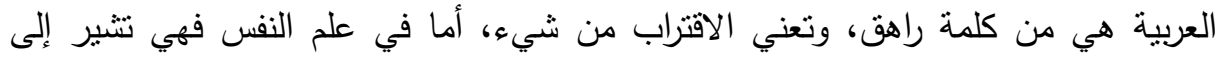


اقتراب الفرد من النضوج الجسماني والعقلي والاجتماعي والنفسي. وتجدر الإشارة هنا إلى أن

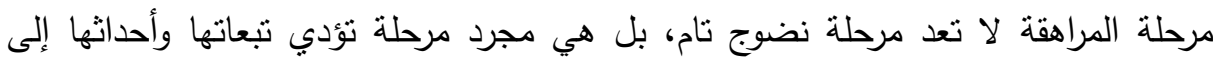
النضوج. تعرف المراهقة: بانها التنرج نحو النضج الجسمي والعقلي والنفسي والاجتماعي والعاطفي وهي فترة تغيرات شاملة وسريعة في نواحي النفس والجسد والعقل والروح وهي مرحلة انتقال من بن ولني

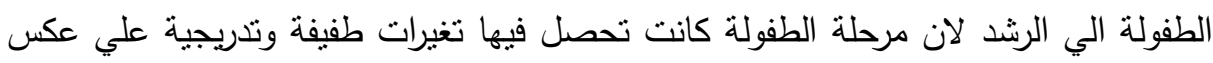
فترة المراهقة التي تجري فيها تغيرات بمعدلات كبيرة جدا، وتتميز فترة المراهقة بتغيرات شاملة

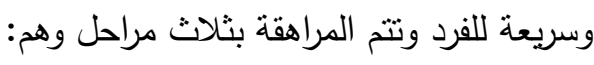
المراهقة المبكرة: وهي تقابل سن الفتي والفتاة في المرحلة الاعدادية. المراهقة المتوسطة: وهي تقابل سن الفتي والفتاة في المرحلة الثانوية.

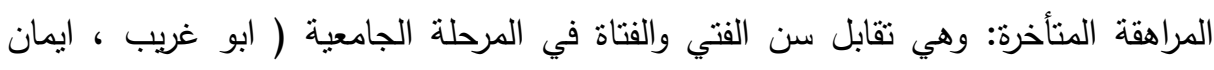

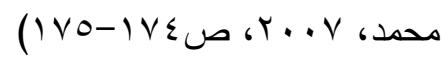

ومن خلال العرض السابق لمفهوم المراهقة يمكن تعريف المراهقة بأنها: مجموعة من التغيرات النمائية السريعة التي تطرأ علي جميع جوانب الثخصية لدي المراهقين الايتام الذين

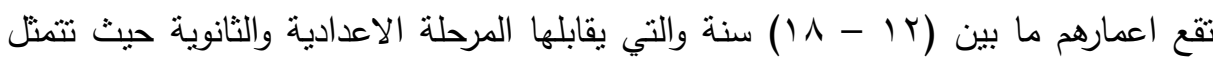
المراهقة المرحلة المبكرة والمتوسطة والتي يتضح فيها أثز الدراسة بشكل واضح.

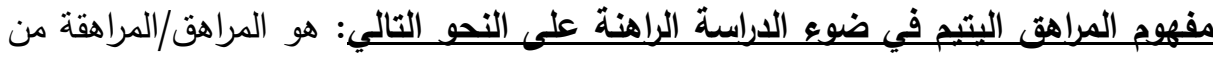
سن الثانية عشر إلى الثامنة عشر هو الذي فقد أحد الوالدين أو كلاهما أو المحروم من فئئ

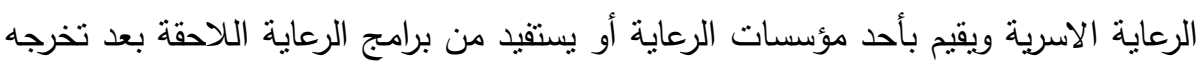

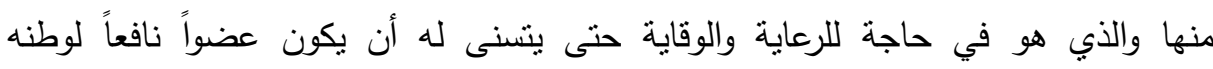

اليتيم The Orphan: واليتم في اللغة العربية كلمة مشتقة من الفعل يتم واليتيم جمعه أيتام ويتامى، وقد يتم الصبي بالكسر ينم، يتما، بالتسكين فيهما واليتم في الناس من قبل الأب، وفي لئه 
البهائم من قبل الأم، والتسمية بهذا الاسم منشأها، عدم الاعتتاء الذي يلاقيه من فقد كفيله،

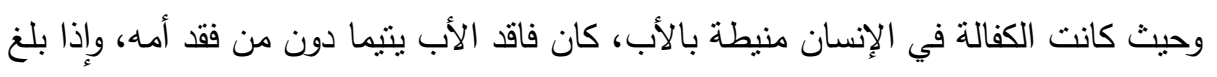

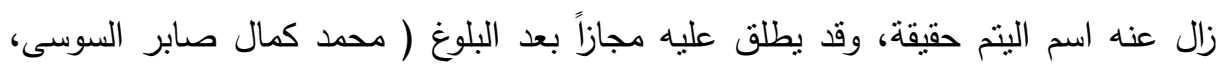

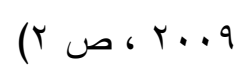

ويمكن تحديد تعريف الطفل المراهق اليتيم إجرائياً في ضوء الدراسة الراهنة كالتالي:

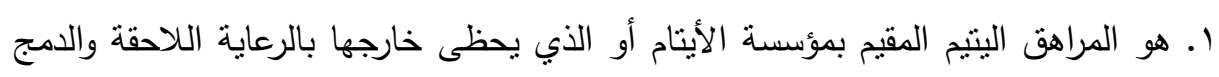

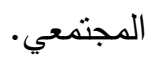

r. هو الطفل المراهق اليتيم الذي يعيش في ظروف اجتماعية سيئة. r. هو الذي يحتاج إلى جودة شاملة من قبل القائمين على رعايته. ـ. هو الذي يحتاج إلى الرعاية والحماية.

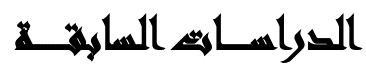

الاراسات العربية التي تناولت الدراسة بالبحث والتفسير:

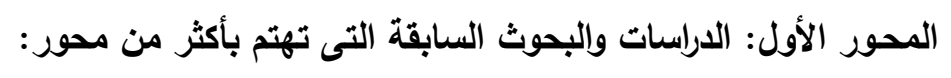

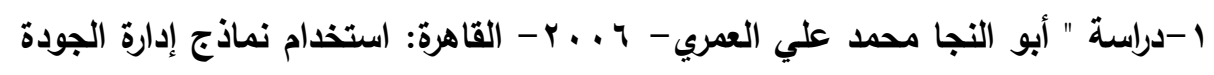

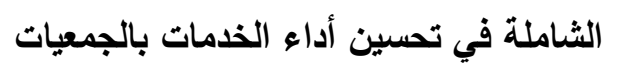

أهداف البحث: حيث هدفت إلى التعرف على إمكانية تطبيق الجودة الثاملة وعلاقة ذلك بلكين بتحسين أداء الخدمات بالجمعية تسأولات البحث: التعرف على آراء الأعضاء حول إمكانية تطبيق إدا رة الجودة الثاملة

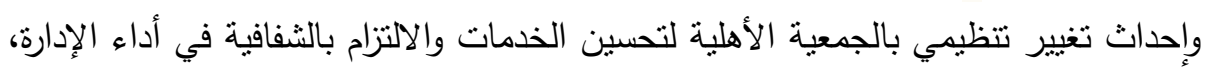
والعاملين للخدمات وتحقيق نظام المساءلة لتحسين أداء الخدمات ونشر ثقافة تحسين جودة الخدمة وتحسين إجراءات تقد الخدمات وإرضاء المستقيدين من الخدمات منهج البحث: تتتمي هذه الدراسة إلى الدراسات الوصفية، وتجهيز المؤسسة بما ينتاسب من واحتياجات المستقيدين. 
أهم النتائج: كان من أهم نتائجها أن هناك اهتمام بالمؤسسات الأهلية بتطبيق نظام الجودة

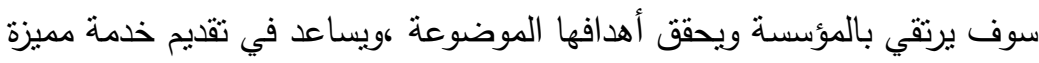
أوجه الاستفادة : تقيد تلك الدراسة الباحثة في التعرف على العلاقة بين تطبيق الجودة الثاملة على إدارة المؤسسة الأهلية ومدى استفادة المؤسسات من تطبيق هذا النظام وعلاقته بتقديم الخدمة للمستقيدين في مدى تحسن الخدمات المقدمة.

r-دراسة (عبدالعزيز الحميان، ؛ 1 بـ- الأردن) " تجرية مركز الدكتور ناصر الرشيد لرعاية الأيتام بحائل نموذجاً " عنوان البحث: تطبيق نظم إدارة الجودة العالمية في مؤسسات رعاية الأيتام

أهداف البحث: استهدفت الدراسة الانطلاق من رؤية نظرية تحليلية ترى في تطبيق الجودة:

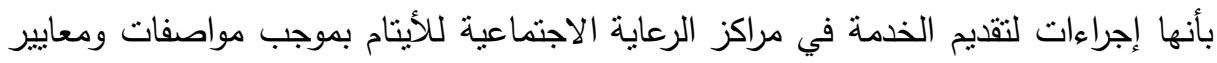
محددة، وذلك من خلال أساليب وتكنيكات حديثة تراعي الظروف الاجتماعية والنفسية لليتيم. فروض البحث: أن مؤسسات الرعاية الاجتماعية قادرة على تطبيق نظم الجودة العالمية، وأن

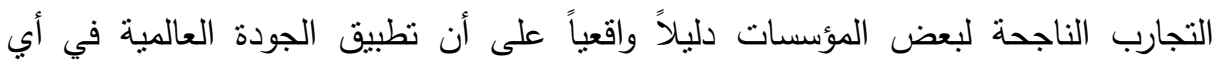
مؤسسة اجتماعية هو أمراً ممكناً ونتائجه نظهر سريعاً مقارنة بالمؤسسات الربحية. منهج البحث: تتنمي هذه الدراسة إلى الدراسات التجريبية. أهم النتائج: أن مؤسسات الرعاية الاجتماعية قادرة على تطبيق نظم الجودة العالمية، وأن تجارب المؤسسات الناجحة دليلاً واقعياً على أن نطبيق الجودة العالمية في أي مؤي مؤسسة

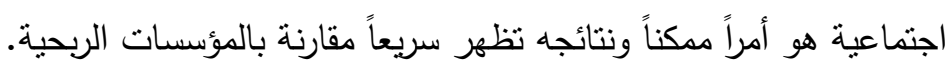
أوجه الاستفادة: استفادت الباحثة من نوصيات الدراسة السابقة في ضوء ضواء الرؤية التحليلية لتجربة مركز الدكتور ناصر الرشيد لرعاية الأيتام بحائل بتطبيقه لنظم الجودة العالمية، وأخيراً لتطبيق نظام الجودة في ضوء نموذج المدخلات والمخرجات. 
r. دراسة "رشاد محمود بلر 9 . . ץ" عنوان البحث: أثر تطبيق مبادئ الجودة الثاملة

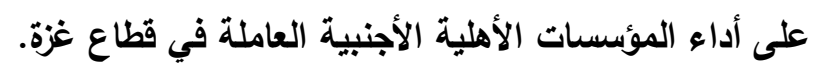

أهداف البحث : معرفة المؤسسات الأهلية لرغبات واحتياجات جمهور المستقيدين والعملاء من الأنيه

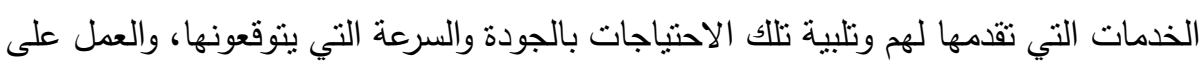
تقديم المكافآت والحوافز للموظفين والعاملين لاى المؤسسة من أجل تشجيعهم على تقديم أفضل ما لديهم وتحقيق الأهداف المطلوبة منهم. تساؤلات البحث: تقييم مدى الكفاءة والفاعلية في الخدمات المقدمة بالمؤسسات الأهلية من الهات خلال تطبيقها لمبادئ الجودة الثاملة. منهج البحث: تتنمي هذه الدراسة إلى الدراسات الوصفية.

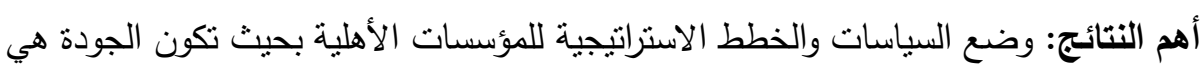

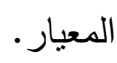
أوجه الاستفادة : استفادت الباحثة من توصيات الدراسة السابقة في تحديد البرنامج الخاص

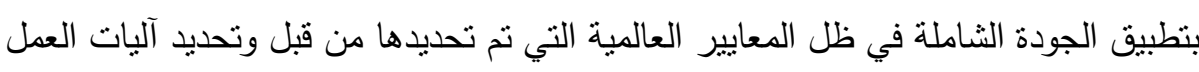

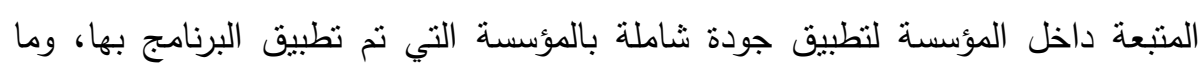

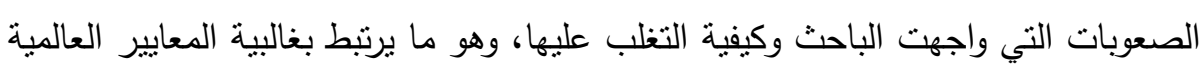
لتحقيق الجودة الخاصة برعاية الطفل اليتيم.

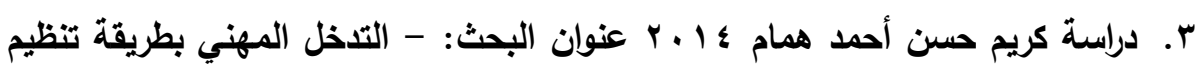

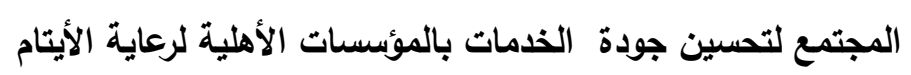

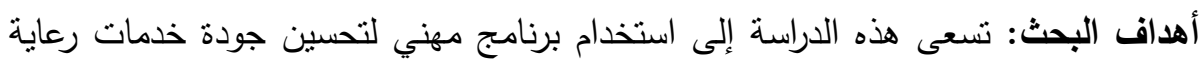
الأيتام داخل المؤسسات الأهلية. فروض البحث: قد يسهم برنامج التدخل المهني في تحسين جودة الخدمات بالمؤسسات الأهلية لرعاية الأطفال الأينام. منهج البحث: تتنمي هذه الدراسة إلى دراسات تقييم عائد التدخل المهني . 
أهم النتائج: بأن اهتمام المؤسسات الأهلية بتطبيق نظام الجودة سوف يرتقي بالمؤسسة ويحقق أهدافها الموضوعة، يساعد في تقديم خدمة مميزة ووضع الخطط والاستراتيجيات والسياسات التي تؤدي لنفس الهدف.

أوجه الاستفادة: استفادت الباحثة من توصيات الدراسة السابقة في أن اهنمام المؤسسات

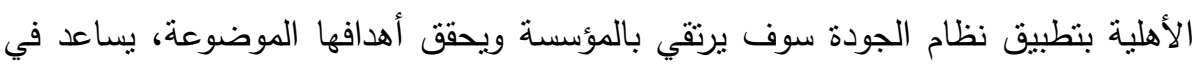

تقديم خدمة مميزة.

المحور الثاني بحوث اهتمت بالأطفال فاقدي الرعاية الاسرية

ا. دراسة شيلا باتيل : Shella Palel , 1990 عنوان البحث: أطفال الشوارع وفتيان القندق وأولادهم من الأهالي سكان وعمال بناء في بومباي كيف يجتمعون في محيطهم

أهداف البحث: التعرف علي مدي تأثثر فقدان الاب والام أو كلاهما والحرمان العاطفي لكلا منهما يؤدى الي ضغوط نفسية قد تمنع الطفل من الاستمرار فى ممارسة شؤون حياته بشكل منوازن. تساؤلات البحث: هل حرمان الطفل من والديه يؤدي الى عدم إثباع الاحتياجات الاجتماعية والنفسية ؟ منهج البحث: اعتمدت الدراسة علي المنهج الوصفي أهم النتائج: ان حرمان الطفل من والديه يؤدي الى عدم إثباع الاحتياجات الاجتماعية لونية والنفسية مما يودى الي عدم التوافق النفسي أن مستوي النمو الاجتماعي لدي الاطفال المحرومين من الرعاية الوالدية أقل فى النمو

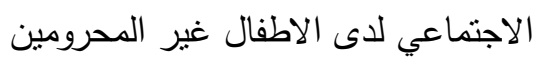
أن الخدمات الصحية المقدمة للأطفال المقيمين بالملاجئ والمقيمين علي ارصفة الثوارع اقل من احتياجاتهم العادية 
أوجه الاستفادة: لقد استفادت الباحثة من الدراسة السابقة حيث أنها تشير إلي أن فقدان الاب

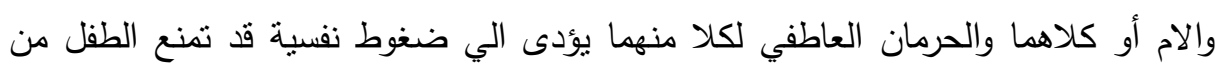
الاستمرار فى ممارسة شؤون حياته بشكل منوازن.

\section{الإطال المظليه}

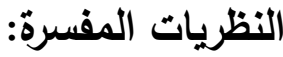

1-نظرية النسق الاجتماعي: تعتبر نظرية النسق الاجتماعي هي اكثر النظريات استخداما

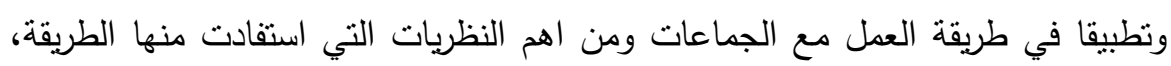
حيث نرى هذه النظرية ان الجماعة نسق مكون من عدة عناصر متفاعلة (عبد العزيز

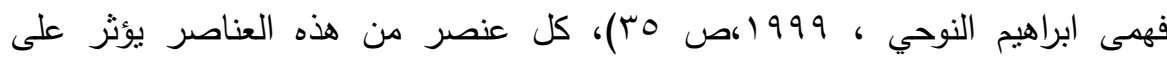

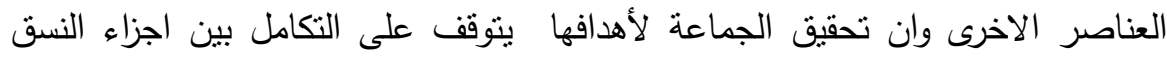

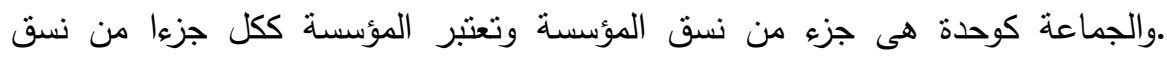

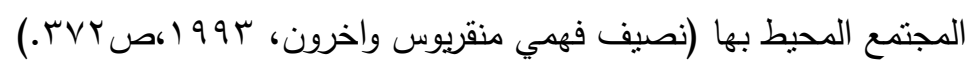

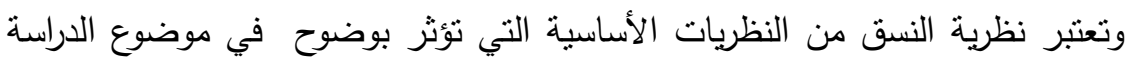

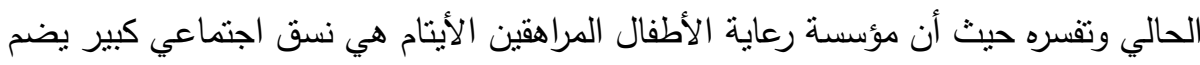

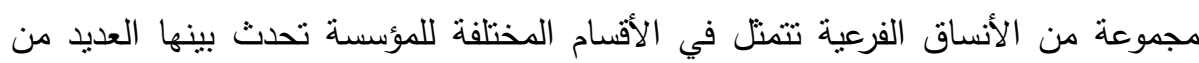
العمليات المختلفة الأفقية والرأسية. 1-لذلك سوف تعتمد الباحثة في هذا البحث علي نظرية النسق الاجتماعي المفاهيم الاساسبة لنظرية النست هي

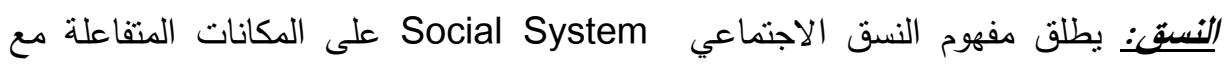

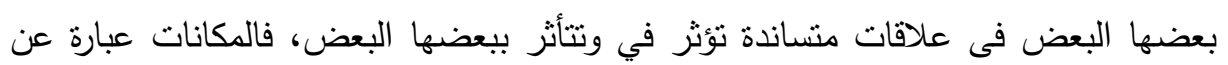

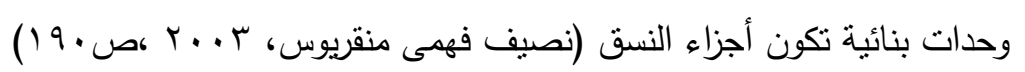
النسق المغلق: هو الذى يستقبل مدخلات من داخلة كالانساق الفيزيقيه الطبيعية وهذا ما أكدته النظريات التظظيمية التقليدية، حيث كانت تتظر الى المنظمة على انها نسق مغلق، وان 
الاهتمام يتركز على الوظائف الداخلية ، دون الاهنمام بالقوى الخارجية وبعملية التغذية العكسية وهى عمليات اساسية فى حياة المنظمات.

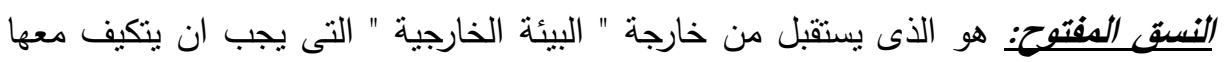

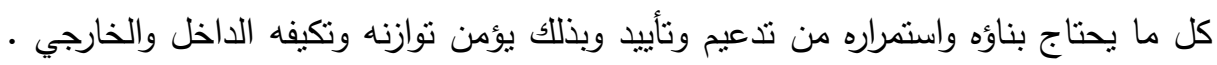
ومن ثم يجب النظر الى المنظمة الاجتماعية على انها نسق اجتماعي مفتوح يوجد بينها وبين

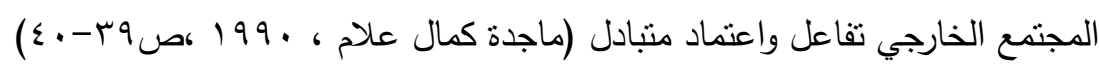

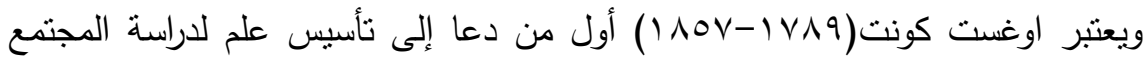

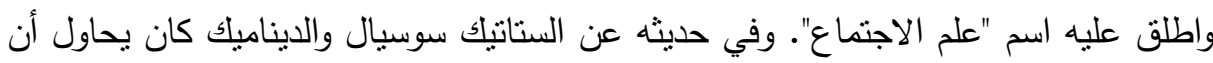
يبحث عن العوامل التي تحفظ للمجتمع استقراره واستمراره. فهو لم يهتم بالتغير بقدر اهتمامه التهاه

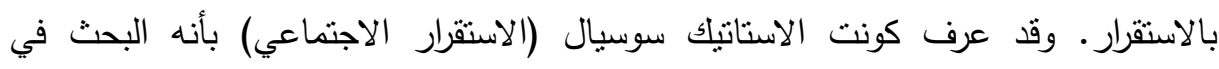

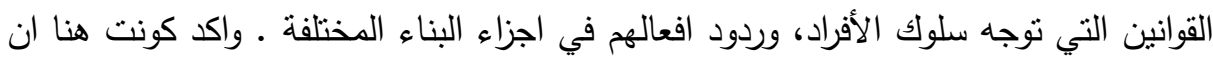
مفهوم التوازن يعني وجود نوع من الانسجام بين اجزاء البناء الاجتماعي، وان حدوث لـاء خلل في

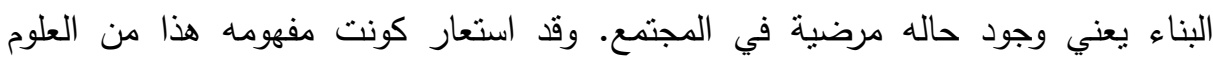
الطبيعية، فكما ان حدوث جرح في اي جزء من اجزاء الكائن الحي يؤدي إلى احداث ألى ألم في مئه

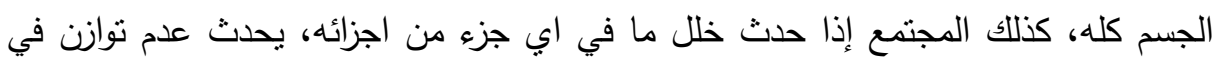

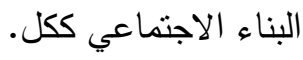

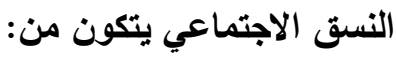
( ) (ب) مجموعة من الاجزاء r) هذه الاجزاء مترابطة مع بعضها البعض على نحو يحقق التساند الوظيفي فيما بينها مكونة بذلك نسقاً اجتماعيا r) توحيد هذه الاجزاء المترابطة فى بيئة نقسم بدرجات متفاوتة من التعقيد

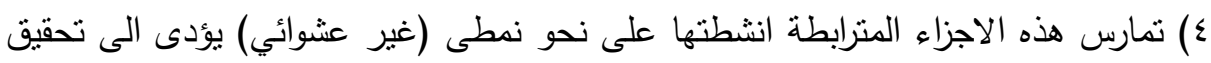
اهداف النسق الاجتماعي 
وتختلف الانساق من حيث حجمها ومن حيث شكل العلاقات بين مكوناتها ومن حيث

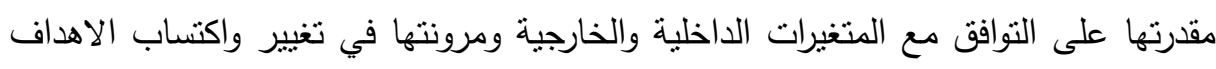

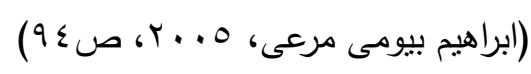
ويقوم هومانز بتحليل النسق الداخلي والخارجي للجماعة من خلال المفاهيم التالية: (1) النشاط: أي ما يفعله اعضاء الجماعة باعتبارهم اعضاء، ويمكن ان بطلق عليه اصطلاح الفعل. r) التفاعل: ويقصد به العلاقة بين النشاط الذى يقوم به اعضاء الجماعة ويتم عن طريق الاتصال اللفظي أو غير لفظي. ץ) العاطفة: وهى مجموعة مشاعر الاعضاء نحو الجماعة التي ينتمون اليها. ع) المعايير : وهى عبارة عن قواعد السلوك التي تنتباها الجماعة بطريقة شعورية أو لاتشعورية

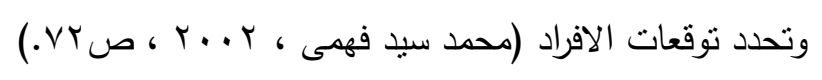

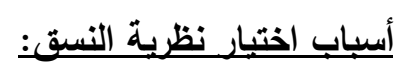

1. اعتبرت هذه النظرية من الإضافات التي قدمها نالكوت بارسونز لنمو وتطور النظرية البنيوية الوظيفية. إن نظرية النسق التي بلور معالمها نالكوت بارسونز تدرس الأنساق

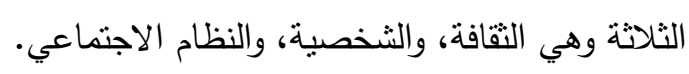

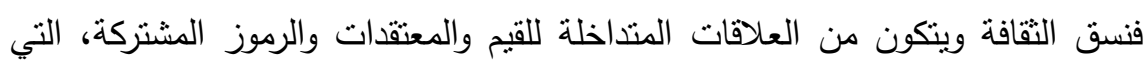

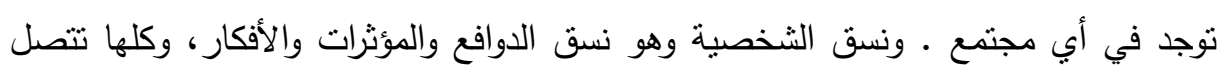

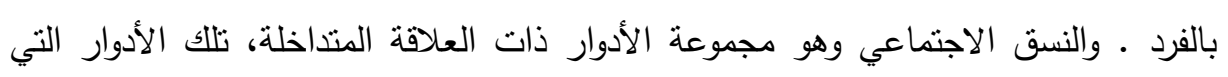

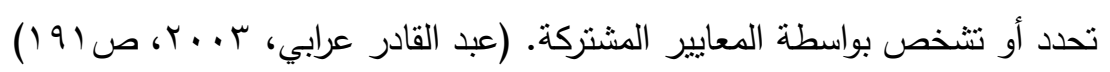

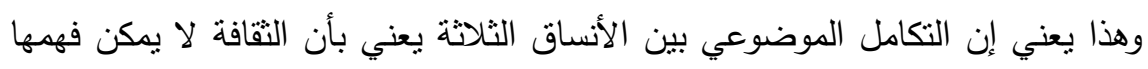

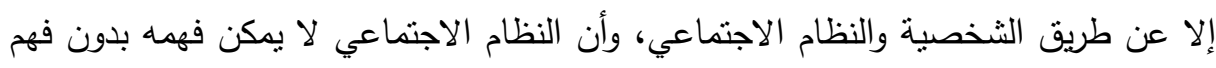
ودراسة واستيعاب النقافة والثخصية. 
r. نظرية الاتصال: تقوم نظرية الاتصال علي فكرة مؤداها ان الاتصال عملية مستمرة تتضمن قيام أحد الاطراف بتحويل افكار ومعلومات معينة إلي رسالة شفوية أو مكتوبة الإنة تتقل من خلال وسيلة اتصال إلي الطرف الاخر (نصيف فهمي منقريوس واخرون،

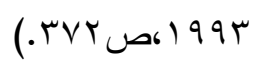

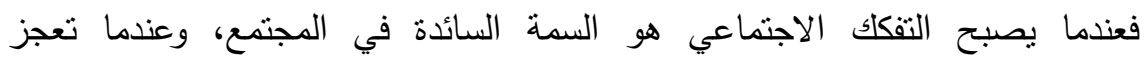

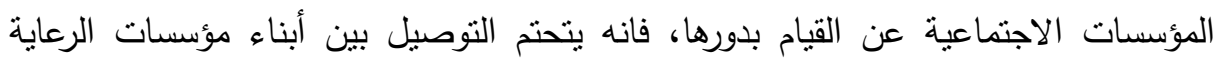

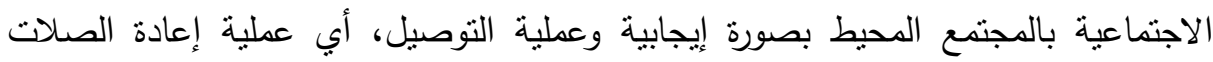
الاجتماعية المنقطعة بين الأفراد والجماعات والمنظمات، ليست مثل عملية رص قوالب وإنما

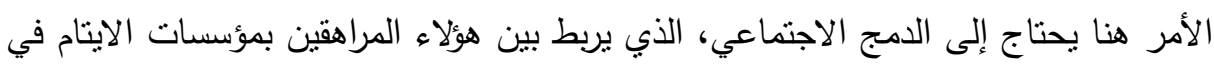

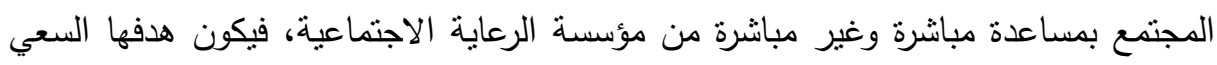

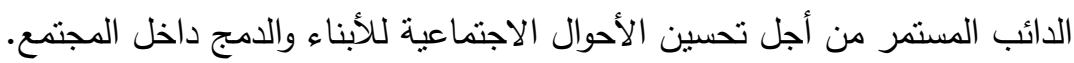
لذا فإن أهدافها واتجاهاتها تتبثق دائما من احتباجات المجتمع، تقوم فلسفتها على نلى نوفير

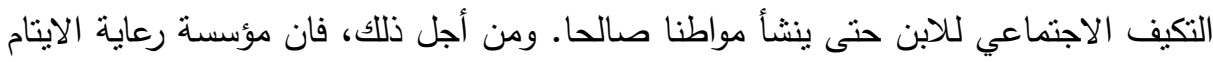

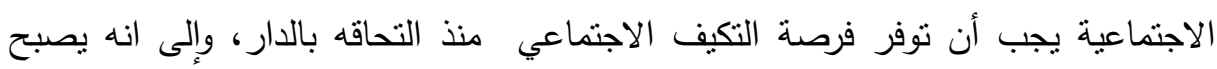
غلاما، ليصبح فيما بعد رجلا ناضجا صالح قادر علي تحمل المسئولية ومنتج. r. نظرية التواصل: وتؤكد النظرية على التواصل والخبرة الانفعالية في حباة الفرد، وأهية العلاقات الاجتماعية وتتمية مهارات التواصل لمساعدة الفرد ليصبح أكثر وعياً، وتعزيز عملية التوافق مع المنطلبات الحياتية وتسهيل عملية التغير من خلال توجيه مهني، لتتمية

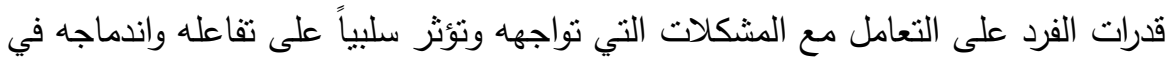

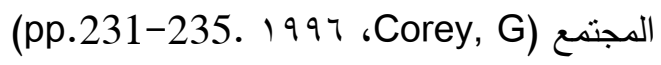

ويتم الاستفادة من نظرية التواصل بما يتفق مع أهداف الدراسة لبناء ثقافة داخلية بين فئة

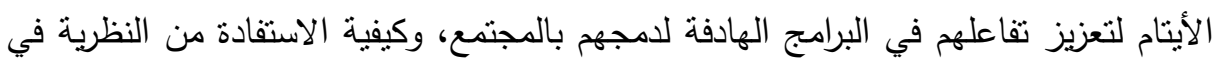


وضع آلية لتوفير المساندة والتعاون بين فئات ومؤسسات المجتمع في التغلب على المعوقات التي تواجه عملية الدمج الاجتماعي لفئة الأيتام .

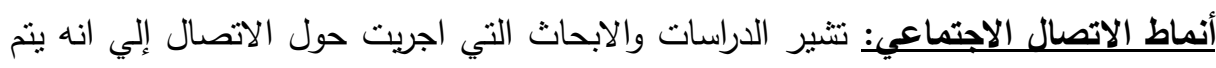
تصنيف هذه الانماط حسب طبيعة شبكة الاتصال وهذه الانماط هي:

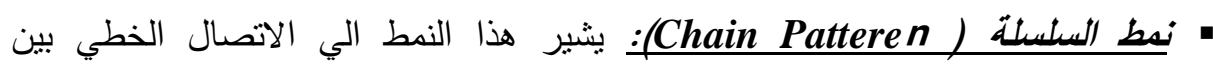
الاعضاء، فيتم الاتصال من فرد لأخر بصورة منتابعة كالسلسلة. • شبكة الاتصال علمي شكل حرف Y Network)Y): ويشبه نمط السلسلة، ولكن يظهر القائد بصورة واضحة في هذا النمط، فالرسالة تمر من الائدائد إلي الاعضاء.

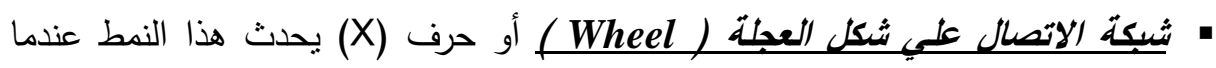

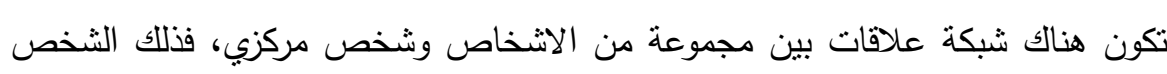
المركزي يسنطيع الاتصال بكل الاعضاء.

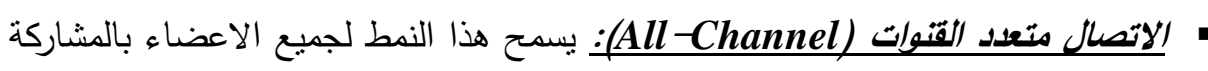
فلا يوجد شخص معين يعتبر المسيطر علي عملية الاتصال.

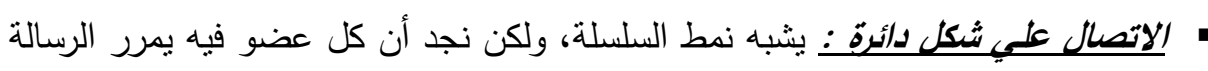
للعضو الذى بجانبه، وهذا النمط يقتصر علي الاعضاء الموجودين في الدائرة (ماجدي لئي

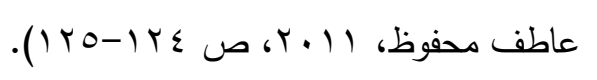

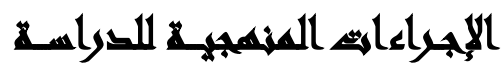

أولاً: نوع الدراسة: دراسة وصفية تستهف تقييم معايير الجودة المطبقة بدور الرعاية لتحسين جودة الخدمات بمؤسسات رعاية الأيتام وذلك لمساعدتها على تحقيق أهدافها الموضوعة.

وتعتبر معايير الجودة من التقنيات الحديثة التي تحتاج إلى تقنين لتلك التقنية واختبار مدى فعاليتها، لذلك أصبحت بحوث التقييم من الأهمية بمكان لأنها تحاول أن تحدد

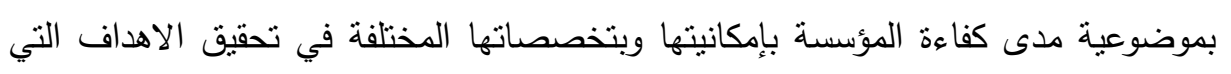


انشئت من اجلها ومدى ملائمة البرامج المستخدمة في تحقيق هذه الأهداف (عبد الحليم رضا

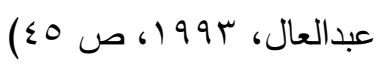
ثانيـاً: منهج الدراسـة المنهج الوصفي: علي الرغم من أن هدف الوصف هو أبسط أهداف العلم إلا أنه أكثرها

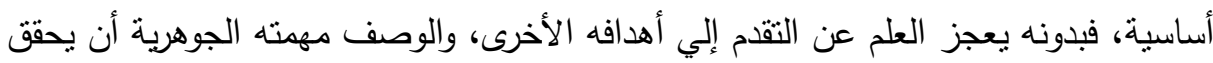
للباحث فهما أفضل لموضوع البحث، ومن ثم استعان الباحث بالمصطلحات التاريخية للنظرية الاجنماعية واستخدم مقياس لقياس جودة الرعاية وكان من الادوات المستخدمة في المقياس (المقابلة،

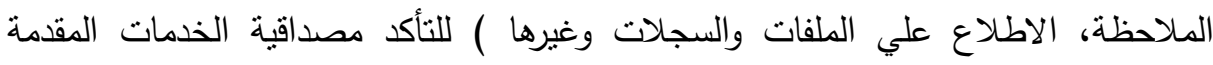
للمراهقين الايتام والمتوفرة في المؤسسة. أما مصدر البيانات فقد تم الحصول عليها من مصدرين هما: أ - (المصادر الثانوية): حيث اتجه الباحث في معالجة الإطار النظري للاراسة إلى مصادر

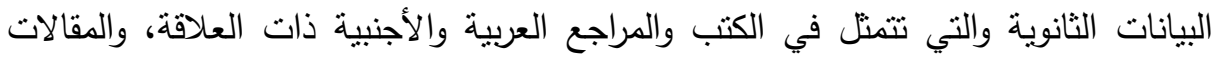
والثقارير، والأبحاث والدراسات السابقة الني تتاولت موضوع الدارسة، والبحث والمطالعة في وليه مواقع الإنترنت المختلفة. ب - ( المصادر الأولية ): وتتمثل في جمع البيانات الأولية ميدانياً، وذللك من خلال استخدام

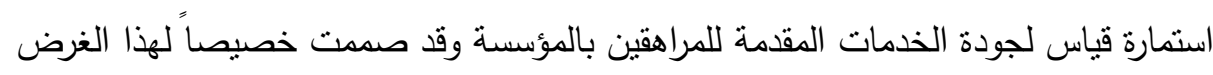
ثالثاً-عينة البحث : قسمت عينة البحث لفئتين:

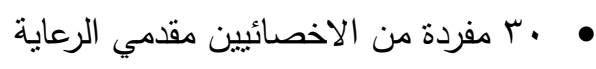

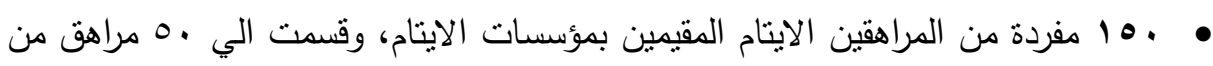

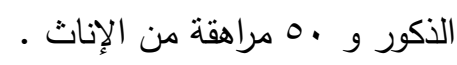


لإيعاً: أدوات الدراسة: استخدم الباحثون أدوات استمارة القياس والمقابلة والملاحظة حيث

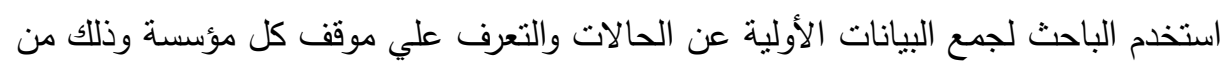

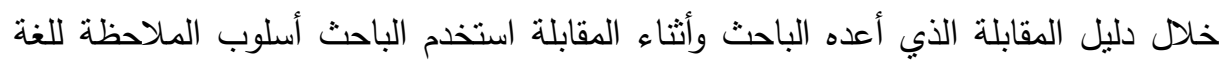
الجسدية للحالة وسلوكياته مع الباحث وطريقة كلامه أيضاً لتحديد مدي ثباته الانفعالي.

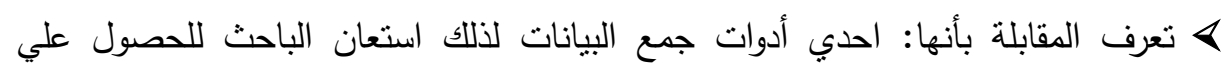

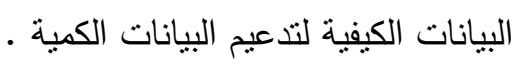

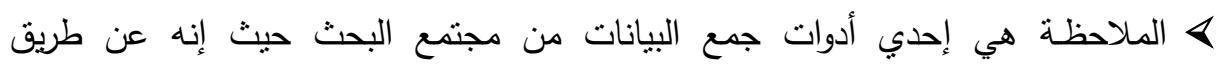

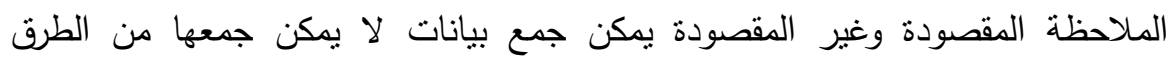
الأخرى.

وصف استمارة القياس: بنيت استمارة القياس علي أساس الاربعة مجالات لجودة مؤسسات

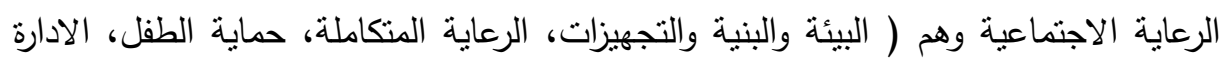
الفعالة) وتكونت استمارة الاخصائيين مقدمي الرعاية من لــ سؤال، بينما تكونت استمارة

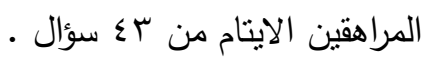

استخدم الباحثون المنهج الوصفي باستخدام عينة عشوائية منتظمة. استخدم الباحثون

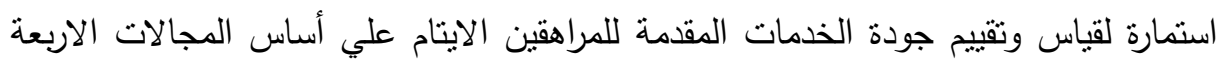

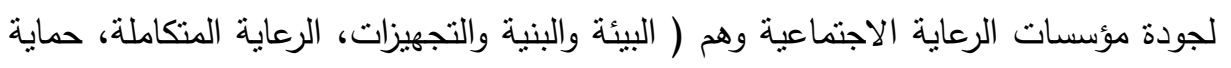

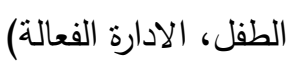

\section{التحليل بمعامل ألفا كرونباخ للحكم علي صدق وثبات استمارة القياس:}

أولاً: صدق استمارة القياس: وضع استمارة للقياس مع الدكتور المشرف علي الربات الرسالة للتأكد من سلامة هدف القياس وهو تقييم جودة الخدمات المقدمة للمبحوث في دور الرعاية. ثانياً: ثبات استمارة القياس: تم استخدام معامل ألفا كرو نباخ للحكم علي ثبات استمارة القياس وصلاحيتها للتطبيق حيث كلما زادت قيمة ألفا زادت درجة الثبات والصدق من اسئلة المقياس، وقد جاءت بالنتائج التالية: 


\begin{tabular}{|c|c|c|c|}
\hline عدد مؤشرات القياس & معامل ألفا كرو نباخ & المجال & م \\
\hline 10 & .873 & مجال البيئة والبنية والتجهيزات & 1 \\
\hline 16 & .898 & مجال الرعاية المتكاملة & $r$ \\
\hline 6 & .939 & محال حماية الطفل & $r$ \\
\hline 15 & .855 & مجال الادارة الفعالة & $\varepsilon$ \\
\hline
\end{tabular}

وهذا يعني قوة صدق وثبات استمارة القياس حيث تجاوزت 100 في معامل الفا وهذا.

يثبت قوة استمارة القياس.

خامساً: مجالات الدراسة: إن اختيار مجالات الدراسة من الخطوات المنهجية التي لا يمكن

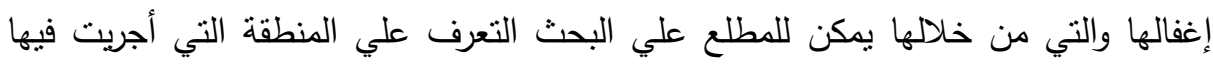
الدراسة والأفراد المبحوثين ( عينة الدراسـة )، و الفترة الزمنية التي أجريت فيها الدراسة وعليه

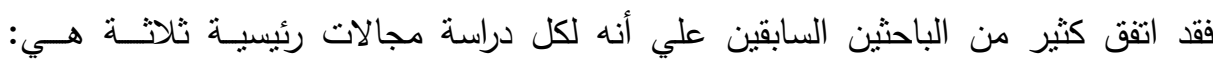
(المجال البشري، والمجال المكاني، والمجال الزمني ) ).

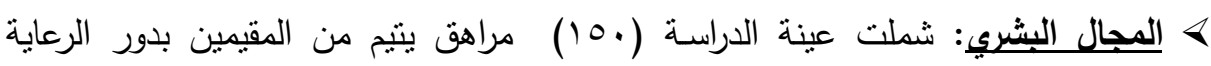

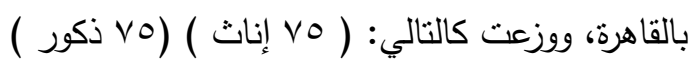
وايضا نم التطبيق علي عينة قوامها (·r) من الاخصائيين العاملين بدور الرعاية.

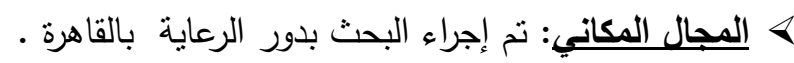

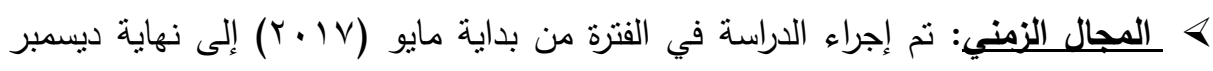

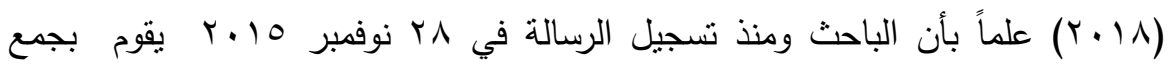
المادة العلمية، وتأصيل المفاهيم والنظريات والدراسات المرتبطة بموضوع البحث، وهى فئل فترة جمع التراث النظري للاراسة حتى تقوم على أسس موضوعية.

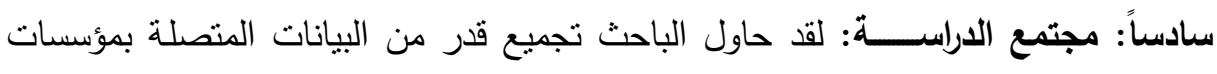

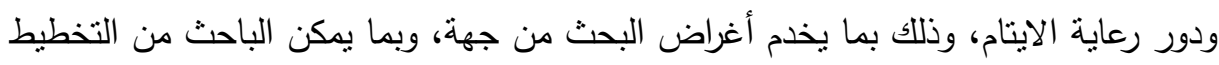
لعملية اختيار مجتمع البحث، وقد حدد الباحث بعد ذلك دور الرعاية ونم اختيارها بمحافظة

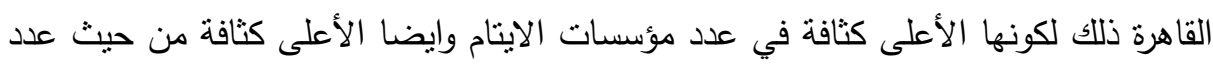

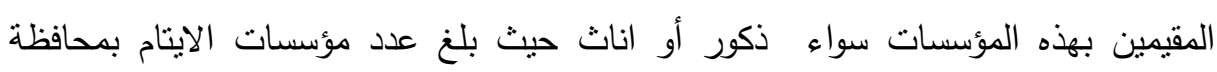




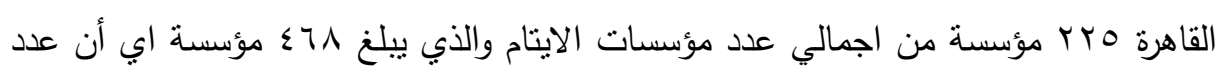

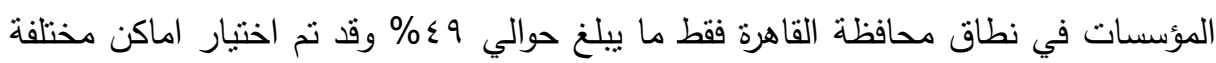
من حيث الموقع الجغرافي لتحديد مدي نأثير البيئة علي هذه المؤسسات فقد نمت فئن الدراسة بثلاث احياء متباينة وهي (مؤسسات في حي المعادي، واخري بعين شمس، وثالثة بحي مصر هئر القديمة)

سابعاً: حجم عيـــة الاراسـة: كانت هنالك مواصفات لدي الباحث عند اختيار عينــة الدراســة من هذه الثروط:

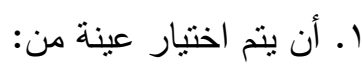
أ- الاخصائيين مقدمي الرعاية بدور رعاية الايتام

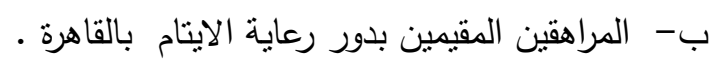
r. أن يتم اختبار أفراد العينة من الجنسين ( الذكور ـ الإناث ).

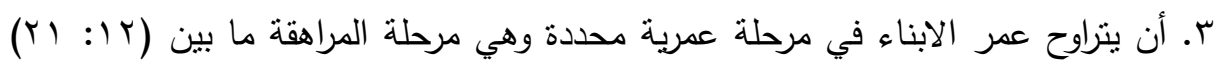

وقد بلغ حجم العينة الكليـة (10 (1) مراهق يتيم من الذكور والإنـاث وقسمت بالتساوي

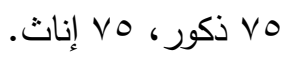

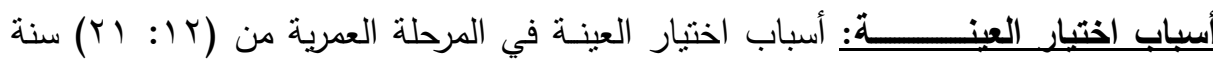
في هذا البحث يرجع إلي رغبة الباحث في نقييم الخدمات المقدمة لفئة معينة وهي فئة فئن المراهقين بدور الرعاية محل الدراسة وذلك لان هذه الفئة نواجه تحديات كبيرة في المجتمع بعد فئد

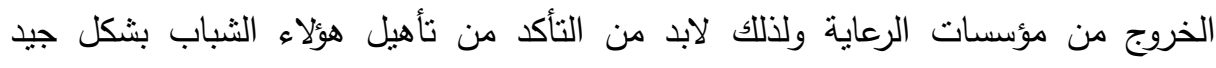

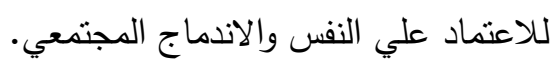

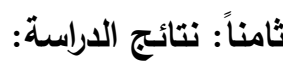
نتائج البحث: بإجراء البحث على مؤسسات الرعاية الاجتماعية لرعاية الايتام تنين وجود

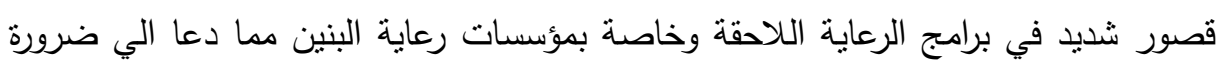
تظوير معايير الايتام والتركيز علي نظم وبرامج الرعاية اللاحقة وضرورة الزام المؤسسات 
بتطبيق هذه البرامج وفق اطار زمني محدد في سبيل تحقيق الهدف من المؤسسة بتأهيل هؤلاء

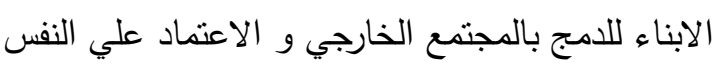
فقد أكدت نتائج الدراسة الخاصة بالعاملين أن هناك نتائج سلبية في مجال الرعاية المتكاملة وانعكاسها بصورة سلبية وقصور شديد في برامج الرعاية اللاحقة . كما أوضحت نتائج الدراسة للأبناء المبحوثين بالدراسة عدم التأهيل الجيد للأبناء لمغادرة

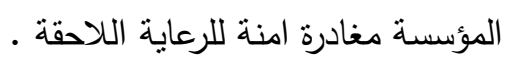
وتبين أن المعايير المطبقة علي هذه المؤسسات لم يدرج بها مؤشرات كافية لبرامج

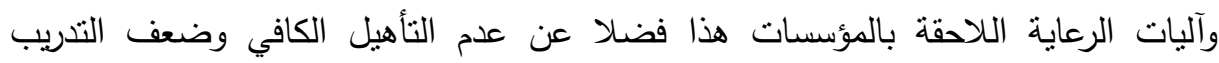
للعاملين مع هؤلاء الثباب للتعامل معهم في هذه المرحلة الحرجة. جداول توضح كيف تم تقسيم العينة: تم تقسيم العينة إلي فئتين الفئة الأولي الاخصائيين بدور الرعاية، الفئة الثانية الذكور والإناث من المراهقين الايتام بدور الرعاية.

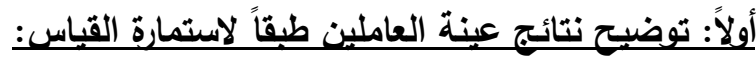

\begin{tabular}{|c|c|c|c|}
\hline النسبة التراكمية & نسبه مئوية & التكرار & النوع \\
\hline 43.3 & 43.3 & 13 & ذكر \\
\hline 100.0 & 56.7 & 17 & انثي \\
\hline & 100.0 & 30 & Total \\
\hline
\end{tabular}

\begin{tabular}{|c|c|c|c|}
\hline النسبة التراكمية & نسبه مئويـة & التكرار & السن \\
\hline 16.7 & 16.7 & 5 & أقل من Yo \\
\hline 60.0 & 43.3 & 13 & $25-35$ \\
\hline 83.3 & 23.3 & 7 & $35-45$ \\
\hline 93.3 & 10.0 & 3 & $45-55$ \\
\hline 100.0 & 6.7 & 2 & م0 فاكثر \\
\hline & 100.0 & 30 & Total \\
\hline
\end{tabular}




\begin{tabular}{|c|c|c|c|}
\hline النسبة التراكمية & نسبه مئوية & التكرر & الوظيفة \\
\hline 3.3 & 3.3 & $\overline{1}$ & مشرف \\
\hline 70.0 & 66.7 & 20 & اخصائي \\
\hline 80.0 & 10.0 & 3 & مسئول حماية \\
\hline 100.0 & 20.0 & 6 & مدير \\
\hline & 100.0 & 30 & Total \\
\hline
\end{tabular}

\begin{tabular}{|c|c|c|c|}
\hline التسبة التراكمية & نسبيه مئوية & التكرار & مدة العمل بالمؤسسة \\
\hline 13.3 & 13.3 & 4 & اقل من سنة \\
\hline 36.7 & 23.3 & 7 & من سنة الى كاسنوات \\
\hline 63.3 & 26.7 & 8 & منس الى ه سنوات \\
\hline 100.0 & 36.7 & 11 & اكثر من ه سنوات \\
\hline & 100.0 & 30 & Total \\
\hline
\end{tabular}

ثانياً: توضيح نتائج عينة المراهقين طبقاً لأسئلة الاستمارة:

جدول: يبين نتائج مؤشرات معايير الجودة بمجال البيئة والبنية والتجهيزات

\begin{tabular}{|c|c|c|c|c|c|c|c|}
\hline الترتيب & الانحراف & المستوسط & نعم & الي حل & ע & حجم العينة . & \\
\hline \multirow{2}{*}{ r } & \multirow{2}{*}{.056 } & \multirow{2}{*}{2.37} & 73 & 59 & 18 & \multirow{2}{*}{ موقع الدار بعيد عن مصادر } & \multirow[b]{2}{*}{1} \\
\hline & & & 48.7 & 39.3 & 12.0 & & \\
\hline \multirow{2}{*}{1} & \multirow{2}{*}{.050 } & \multirow{2}{*}{2.23} & 49 & 87 & 14 & \multirow{2}{*}{ تتتاسب تجهيزات غرف العمرية الأطفال } & \multirow[b]{2}{*}{ r } \\
\hline & & & 32.7 & 58.0 & 9.3 & & \\
\hline \multirow{2}{*}{$\wedge$} & \multirow{2}{*}{.042} & \multirow{2}{*}{2.64} & 98 & 50 & 2 & \multirow{2}{*}{ هناك مكان مجهز لممارسة } & \multirow[b]{2}{*}{ T } \\
\hline & & & 65.3 & 33.3 & 1.3 & & \\
\hline \multirow{2}{*}{1.} & \multirow{2}{*}{.045} & \multirow{2}{*}{2.71} & 113 & 30 & 7 & \multirow{2}{*}{ توجد علامات أو لوحادات } & \multirow[b]{2}{*}{$\varepsilon$} \\
\hline & & & 75.3 & 20.0 & 4.7 & & \\
\hline \multirow{2}{*}{ r } & \multirow{2}{*}{.064} & \multirow{2}{*}{2.44} & 93 & 30 & 27 & \multirow{2}{*}{ عنابر الأطفال تجدد بشكل } & \multirow{2}{*}{ 。 } \\
\hline & & & 62.0 & 20.0 & 18.0 & & \\
\hline \multirow{2}{*}{ V } & \multirow{2}{*}{.054} & \multirow{2}{*}{2.57} & 100 & 36 & 14 & \multirow{2}{*}{ تجيزات الدار توفر اشتراطات } & \multirow{2}{*}{7} \\
\hline & & & 66.7 & 24.0 & 9.3 & & \\
\hline \multirow{2}{*}{$\varepsilon$} & \multirow{2}{*}{056} & \multirow{2}{*}{2.49} & 90 & 44 & 16 & \multirow{2}{*}{ يوجد بالمؤسسة عدد كافي من } & \multirow[b]{2}{*}{ V } \\
\hline & & & 60.0 & 29.3 & 10.7 & & \\
\hline 0 & .057 & & 96 & 37 & 17 & توجد أجهزة إنذار مبكر في & $\Lambda$ \\
\hline 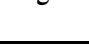 & .051 & 2.53 & 64.0 & 24.7 & 11.3 & حالة الكوارث والأزمات & \\
\hline 9 & 040 & 26 & 97 & 52 & 1 & حمامات الدار نتوافر بها & 9 \\
\hline 4 & .040 & 2.64 & 64.7 & 34.7 & .7 & عناصر الأمن والأمان & 4 \\
\hline 7 & 04 & & 83 & 63 & 4 & ينم إجراء صيانة دورية لمرافق & 1, \\
\hline 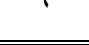 & $.04 J$ & 2.03 & 55.3 & 42.0 & 2.7 & المؤسسة & 1. \\
\hline
\end{tabular}


ونستنج من الجدول السابق:

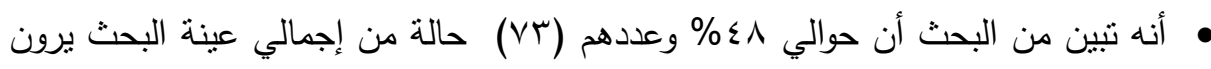

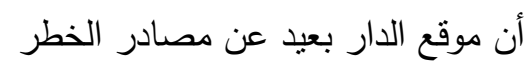

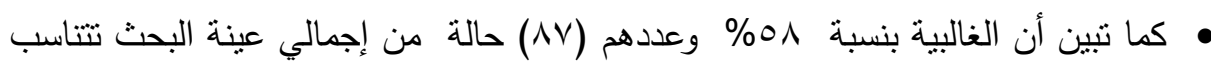

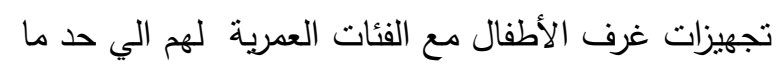
• وتنين أن حوالي 7 \% و وعددهم (91) حالة من إجمالي العينة برون أن هناك مكان مجهز لممارسة الأنشطة

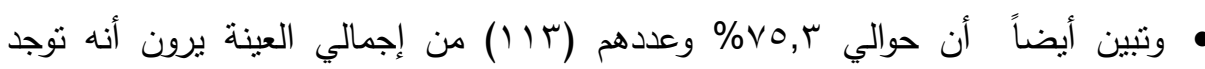

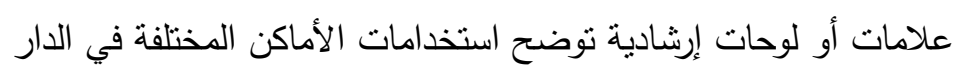

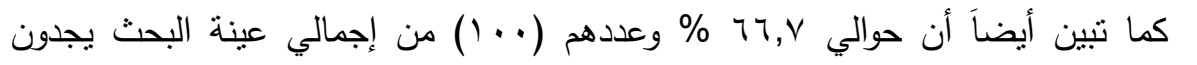
تجهيزات الدار توفر السلامة للأطفال وفقا لاتشتراطات الحماية المدنية • وتبين أن حوالي •, • \% \% وعددهم (•9) حالة من إجمالي العينة تري انه يوجد بالمؤسسة عدد كافي من الحواسب الآلية وتبين أن حوالي •,rج \% وعددهم (r9) حالة من إجمالي العينة تري أن عنابر الأطفال تجدد بشكل دوري

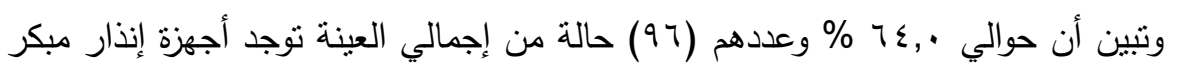
في حالة الكوارث والأزمات

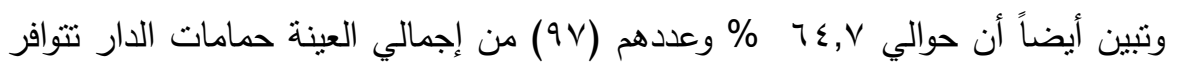
بها عناصر الأمن والأمان.

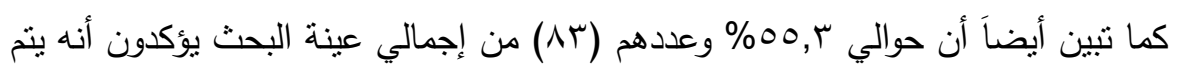

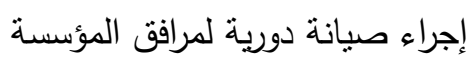
ونجد مما يتضح من الجدول السابق أن تقييم مجال البيئة والبنية والتجهيزات بشكل متوسط

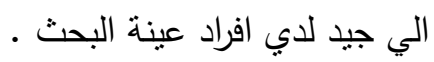


• ونستتج من ذلك انه بالرغم من تباين اماكن المؤسسات في التطبيق الا ان المراهقين

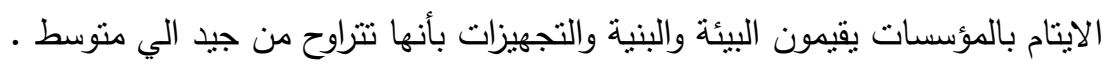

تفسير النتائج ومناقشتها:

أكدت نتائج الدراسة المطبقة علي المراهقين الايتام والتي نستهدف تقييم جودة الخدمات

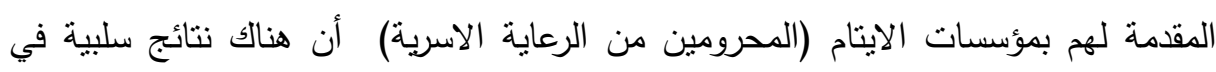

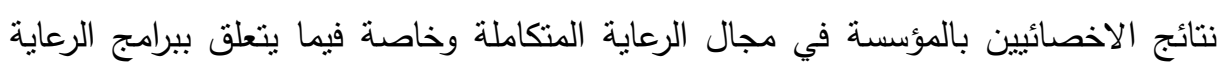
اللاحقة وانعكاسها بصورة سلبية علي الرعاية والتأهيل للأبناء بالمؤسسات.

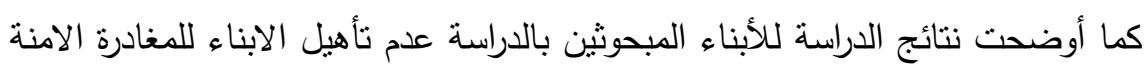
للرعاية اللاحقة .

كما نبين أن المعايير المطبقة علي هذه المؤسسات لم يدرج بها مؤشرات كافية لبرامج

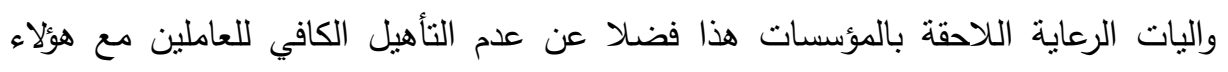

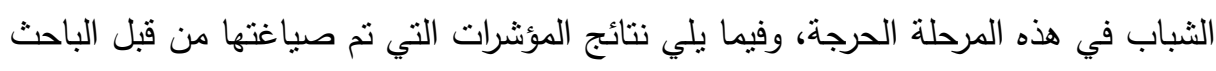

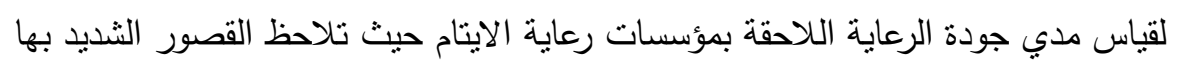

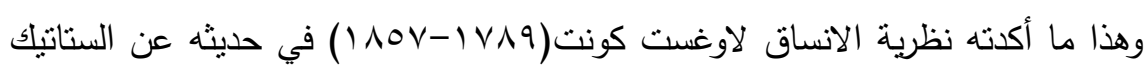
سوسيال والديناميك كان يحاول أن يبحث عن العوامل التي تحفظ للمجتمع استقراره واستمراره . فهو لم يهتم بالتغير بقدر اهتمامه بالاستقرار . وقد عرف كونت الاستانيك سوشيال (الاستقرار

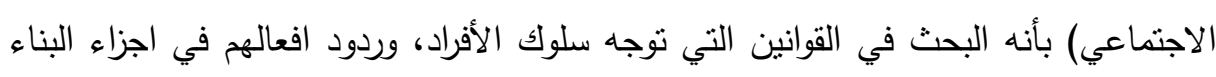
المختلفة. واكد كونت هنا ان مفهوم التوازن يعني وجود نوع من الانسجام بين اجزاء التئه البناء الاجتماعي، وان حدوث خلل في البناء يعني وجود حاله مرضية في المجتمع وتعد معايير

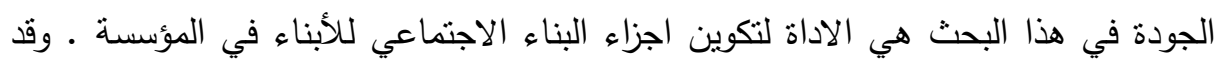

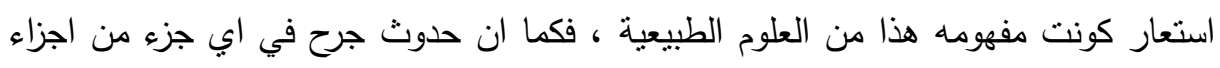

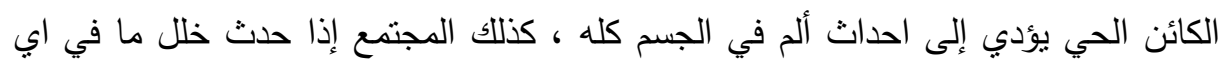
جزء من اجزائه، يحدث عدم توازن في البناء الاجتماعي ككل، وبالفعل هذا ما حدث إثى عندما لها

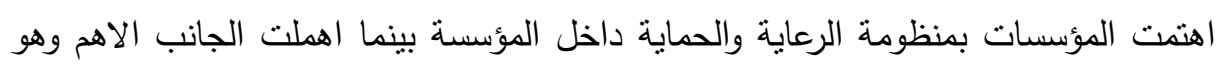

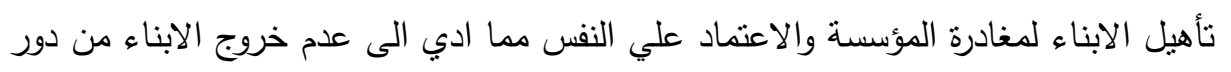


الرعاية عند بلوغهم سن الرعاية اللاحقة واعتمادهم اعتمادا كلبا علي المؤسسة والوزارة لتدبير

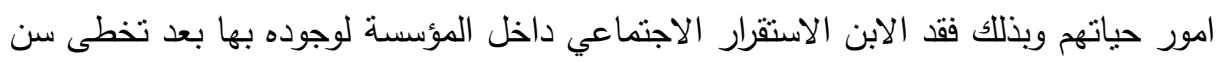

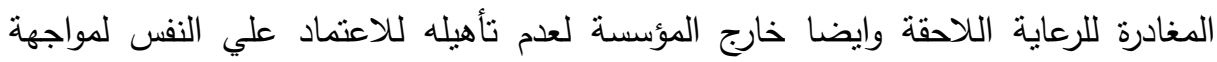

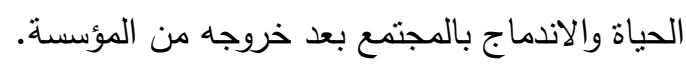

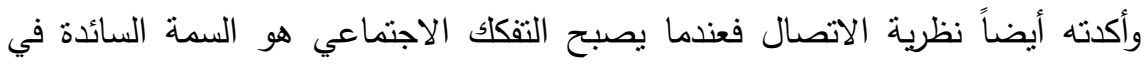
المجتمع وعندما تعجز المؤسسات الاجتماعية عن القيام بدورها فانه يتحتم التوصيل بين أبناء

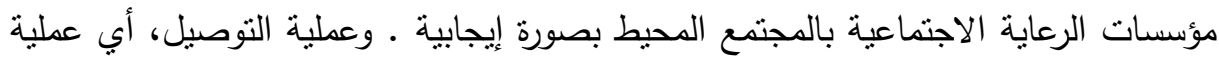

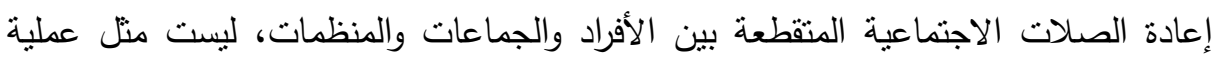
رص قوالب وإنما الأمر هنا بحتاج إلى التأهيل للامج الاجتماعي، الذي يربط بين هؤلاء المراهقين بمؤسسات الايتام في المجتمع بمساعدة مباشرة وغير مباثرة من مؤسسة الرعاية الاجتماعية، فيكون هدفها السعي الدائب المستمر من أجل تحسين الأحوال الاجتماعية للأبناء والدمج داخل المجتمع ولتأهيلهم لمغادرة امنة من المؤسسة عند بلوغهر سن الدئه الرعاية اللاحقة. كما نجد أيضاً أن نتائج البحث تتسق مع نتائج كثير من الدراسات السابقة مثل: أولاً: دراسة استخدام نماذج إدارة الجودة الثناملة في تحسين أداء الخدمات بالجمعيات الأهلية

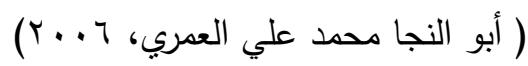
حيث أكلت أن اهتمام بالمؤسسات الأهلية بتطبيق نظام الجودة سوف يرتقي بالمؤسسة ويحقق

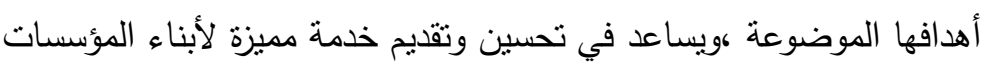

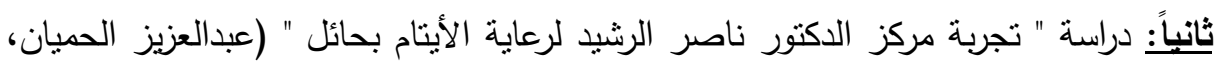

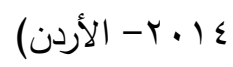

وتؤكد هذه الدراسة أن مؤسسات الرعاية الاجتماعية قادرة على تطبيق نظم الجودة العالمية،

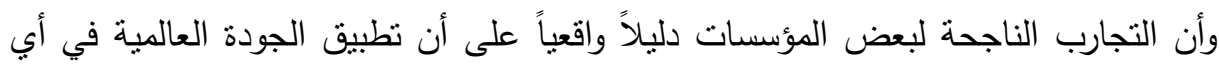
مؤسسة اجتماعية هو أمراً ممكناً ونتائجه تظهر سريعاً مقارنة بالمؤسسات الربحية. 
التوصيات: في ضوء النتائج التي توصلت إليها الدراسة الحالية يوصي الباحث بما يلي:

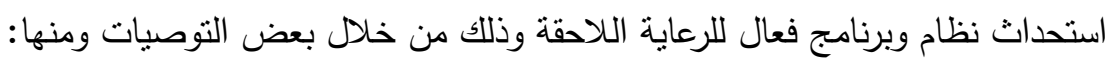

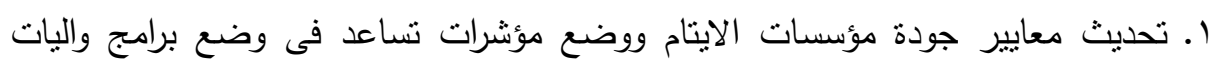
واضحة للرعاية اللاحقة r. تواجد الأخصائي الاجتماعي مسئول الخريجين بصفة دورية بثقق الأبناء لتقديم الدساندة واجراء تقييم أسبوعي لقياس مستوى النمو العقلي وروح التعاون والانتظام بالدراسة والعبادات وما يتبع من بنود التقيبيم. r. وضع خطة للرعاية اللاحقة للمراهق بمشاركته وفقا لاحتياجاته وقدراته مع مثابعتها بصفة

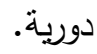
ع. الاتفاق مع المنظمات الخارجية لتنريب الأبناء بصفة مستمرة وتقديم يد العون والتتشيع لمالأبناء المنتربين. 0. تدريب الأبناء التي تتوافق دراستهم واستعدادهم العقلي والعضلي على الأعمال المهنية مثل

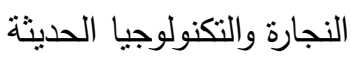
7. متابعة المتدربين من الابناء بأماكن ندريهم من قبل المسئول التعليمي والأخصائي

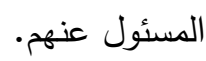
V. مساعدة الأبناء القادرين على إدارة مشروع صغير خاص بالجهز والفكر والمال كلما أمكن.

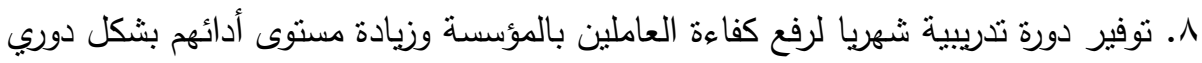

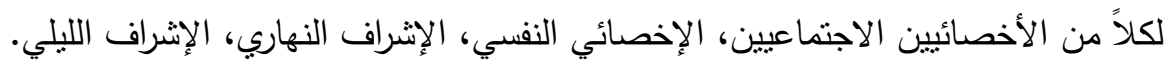

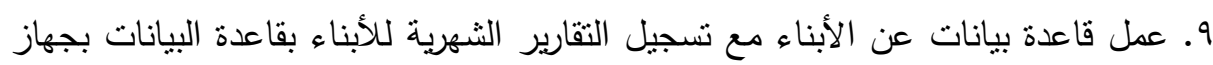

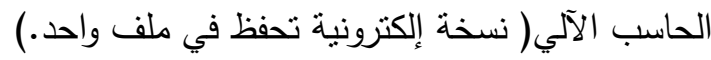
• 1. زيادة عدد الأخصائيين الاجتماعيين لتحقيق مبدأ الكفاية مع وضع أسس وقواعد الاختيار مع المسئولين عن المؤسسة. ثانياً: البحوث المقترحة: من خلال الننائج الني أسفرت عنها الدراسة يقترح الباحث الدراسات 1. اساليب الرعاية اللاحقة لأبناء مؤسسات الايتنام واثرها علي الاندماج المجتمعي 
r. بافة وتأثيرها علي المجتمع. r. التأهيل المهني لأبناء دور الرعاية الاجتماعية وعلاقته بالاستقرار الاجتماعي والاندماج المجتمعي.

ع. البيئة النفسية لأبناء دور الرعاية وعلاقتها بالتأهيل للرعاية اللاحقة .

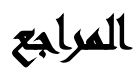

ابراهيم بيومي مرعى: المدخل الى الخدمة الاجتماعية، القاهرة، مركز نور الايمان، ه... ب، ص ص 9

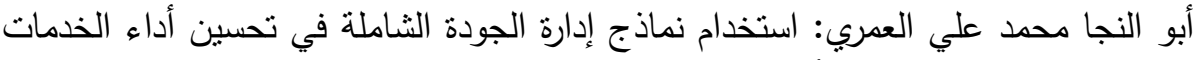
بالجمعيات الأهلية، رسالة ماجستير غير منشورة، كلية الخدمة الاجتماعية،

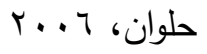

ابو غريب، ايمان محمد: النطور من الطفولة وحتي المراهقة، دار جرير للنشر والتوزيع عمان،

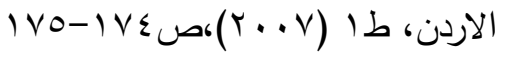

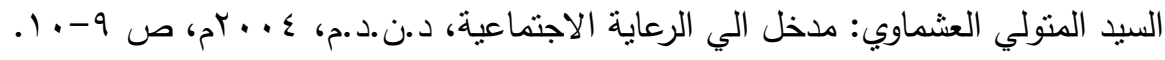
جواهر القنادلي: التقييم في التعليم الجامعي، الجيزة :مركز الخبرات المهنية للإدارة،2009 ، ص 1 ص

رشاد محمود بدر : رسالة ماجستير غير منشورة، الجامعة الإسلامية، غزة، 9 . .ب.

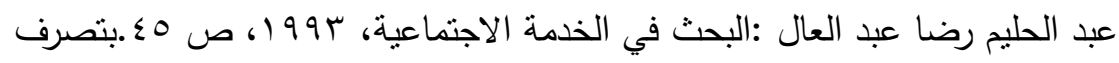

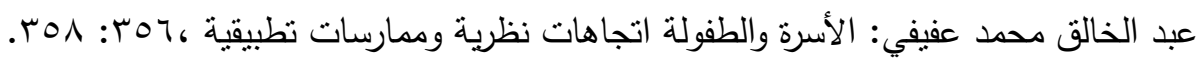

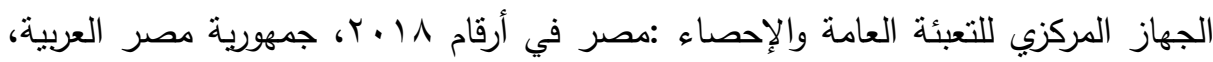

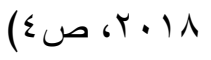

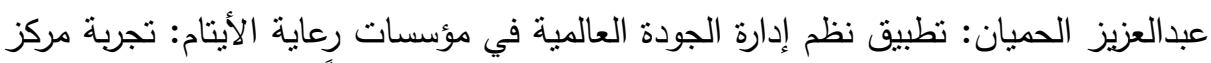

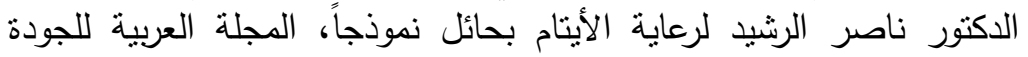

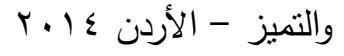

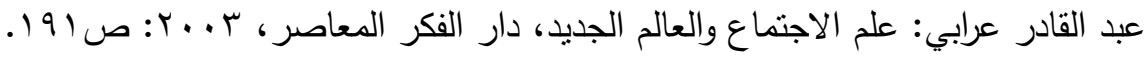

$$
\text { المجلد السابع والأربعون، الجزء الأول، ديسمبر } 19
$$




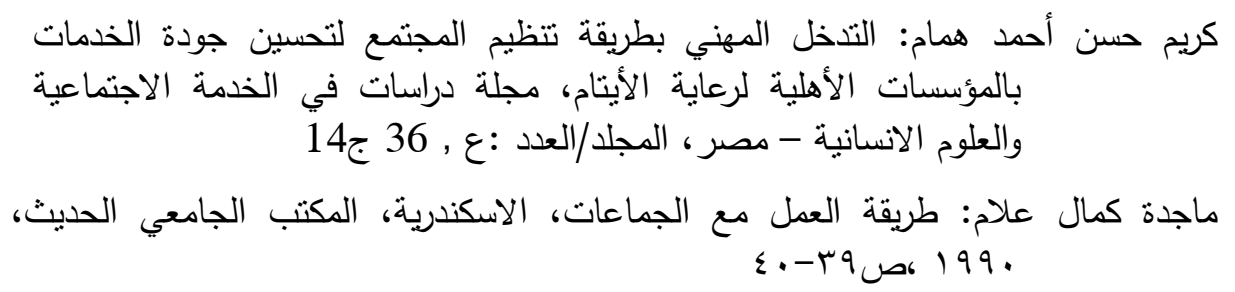

محمد سيد فهمي: مدخل إلي الرعاية الاجتماعية، دار المعرفة الجامعية، الاسكندرية، 997 19، صان

محمد سيد فهمى: طريقة العمل مع الجماعات بين النظرية والتطبيق، الجزء الثالث، الممارسة

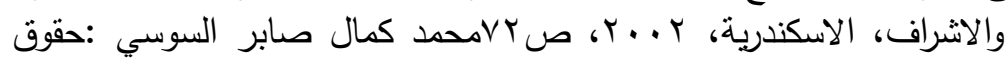

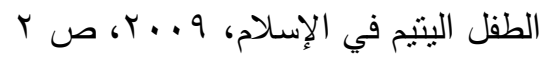

نصيف فهمي منقريوس: النظريات العلمية والنماذج المهنية بين البناء النظري والممارسة في

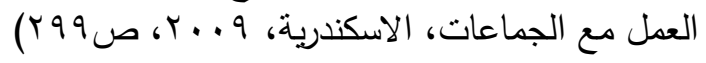

نصيف فهمي منقريوس وآخرون: العمل مع الجماعات وتطبيقاته في الخدمة الاجتماعية،

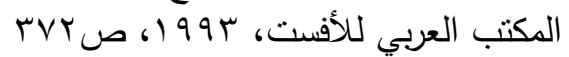

Shella Patel: Street children, Hotel boys and children of parents Dwellers and construction workers in bormbay-How they meet their danily enviroment and urbanizakion J. Article, Vol. (2) (1990).

http://www.un.org/ar/sections/issues-depth/children/index.html https://www.capmas.gov.eg 
مجلة العلوم البيئية

معهد الدراسات والبحوث البيئة - جامعة عين شمس

\title{
AN EVALUATIVE STUDY ON THE QUALITY OF SOCIAL AND INSTITUTIONAL WELFARE PROVIDED TO ADOLESCENT ORPHANS
}

\author{
Mona M. Abdo ${ }^{(1)}$; Amal A. Shams ${ }^{(2)}$ \\ and Mervat G. Shamroukh ${ }^{(3)}$
}

1) Post grad. Institute of Environmental studies and Research, Ain Shams University 2) Faculty of Education, Ain Shams University 3) Faculty of Social Work Helwan University

\begin{abstract}
This study aimed at assessing the quality of social and institutional care provided to orphans, especially adolescents Studies indicate the importance of social care in the education of young people, especially within orphanages Which affects the future of society as a whole, , So I thought that I would provide a pilot assessment that could be of help to researchers, caregivers and decision-makers in order to provide better services and to address the problems of adolescent orphans in social welfare institutions.

The research sample was divided into two categories:

- 30 cases of caregivers

- 150 cases of orphaned adolescents living in orphanages, divided into 50 male adolescents and 50 adolescent girls.

The researchers used the descriptive approach using a regular random sample. The researchers used a questionnaire to measure and evaluate the quality of services provided to adolescent orphans based on the four areas of quality of social welfare institutions (environment, infrastructure, equipment, integrated care, child protection, effective management)
\end{abstract}

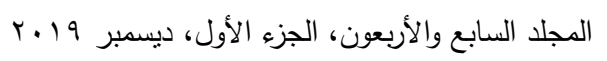


Results: The results of the study of the workers confirmed that there are negative results in the field of integrated care and its negative reflection and severe deficiencies in subsequent care programs.

The results of the study also revealed to the children interviewed in the study that the children are not qualified to leave the institution and leave safe for subsequent care.

It was found that the standards applied to these institutions did not include sufficient indicators for subsequent care programs and mechanisms, As well as inadequate rehabilitation and poor training of staff to deal with these young people at this critical stage

The main Recommendations: The results of the research show that there is a severe shortage in the plans of rehabilitation and aftercare. It is necessary to develop a policy of aftercare and a system that applies to all social care homes for social integration so as not to negatively affect the behavior of children From the inability to rely on self and engage in society 